1 Progress toward the identification and stacking of crucial domestication traits in

2 pennycress

4 Authors

5 Ratan Chopra ${ }^{1}$, Evan B. Johnson ${ }^{1 \dagger}$, Ryan Emenecker ${ }^{1 \dagger}$, Edgar B. Cahoon ${ }^{2}$, Joe

6 Lyons $^{3}$, Daniel J. Kliebenstein ${ }^{4}$, Erin Daniels ${ }^{1 \dagger}$, Kevin M. Dorn ${ }^{1 \dagger}$, Maliheh

7 Esfahanian $^{5}$, Nicole Folstad ${ }^{1}$, Katherine Frels ${ }^{6}$, Michaela McGinn ${ }^{5}$, Matthew Ott ${ }^{6}$,

8 Cynthia Gallaher $^{7}$, Kayla Altendorf ${ }^{6}$, Alexandra Berroyer ${ }^{5}$, Baraem Ismail ${ }^{7}$, James

9 A. Anderson ${ }^{6}$, Donald L. Wyse ${ }^{6}$, Tim Umaslov ${ }^{3}$, John C. Sedbrook ${ }^{5}$, and M.

10 David Marks ${ }^{1 *}$

\title{
Affiliations
}

${ }^{1}$ Department of Plant and Microbial Biology, University of Minnesota, St. Paul, 15 MN 55108 USA.

$16{ }^{2}$ Center for Plant Science Innovation and Department of Biochemistry, University

17 of Nebraska-Lincoln, Lincoln, NE 68588 USA

$18{ }^{3}$ Covercress, Inc. St. Louis, MO 63132 USA

$19{ }^{4}$ Department of Plant Sciences, University of California - Davis, Davis, CA 95616 20 USA

$21{ }^{5}$ School of Biological Sciences, Illinois State University, Normal, IL 61790 USA

$22{ }^{6}$ Department of Agronomy and Plant Genetics, University of Minnesota, St. Paul, 23 MN 55108 USA.

$24{ }^{7}$ Food Science and Nutrition, University of Minnesota, St. Paul, MN 55108 USA

26 *Correspondence to: M. David Marks - marks004@umn.edu

\section{$27{ }^{\dagger}$ Present addresses:}

28 E.B.J. Renewable and Sustainable Energy Institute, University of Colorado,

29 Boulder, CO 80309

30 R.E. Department of Biology, Washington University, St. Louis, MO 63130

31 E.D. Salk Institute for Biological Studies, La Jolla, CA 92037

32 K.M.D. Department of Plant Pathology, Kansas State University, Manhattan, KS 3366506 
36

39 The oilseed species Thlaspi arvense (pennycress) is being domesticated as a

40 new crop that can provide both important ecosystem services and intensify

41 farmland output. Through the use of high throughput sequencing and

42 phenotyping, along with classical mutagenesis key traits needed for pennycress

43 domestication have been identified. Domestication traits identified herein include

44 reduced pod shatter, early maturity, reduced seed glucosinolate levels, and

45 improved oil fatty acid content. By taking advantage of pennycress' close genetic

46 relationship with Arabidopsis thaliana, the causative mutations responsible for

47 each of these traits have been identified. These mutations have been used to

48 develop molecular markers to begin to stack the traits into individual lines. 
52 Tremendous gains in crop yields have been achieved through a combination of

53 increased fertilizer use, crop breeding, and improved agronomic practices (2014).

54 However, the long-term sustainability of crop production using current farming

55 practices is threatened by several factors. In intensive cropping systems, such as

56 the corn-soybean rotation in the Midwestern United States, only $40-60 \%$ of the

57 applied nitrogen fertilizer is taken up by plants (Wortmann et al. 2011). Much of

58 the remaining nitrogen is released as greenhouse gases or pollutes surface and

59 ground waters resulting in the eutrophication of streams and lakes, the creation

60 of dead zones in coastal regions, and the contamination of wells in rural

61 communities (Robertson and Vitousek 2009). Another looming threat to

62 agricultural production is the emergence of herbicide tolerant weeds, including

63 weeds tolerant to glyphosate (Heap 2014). The use of glyphosate resistant crops

64 over the past twenty-five years enabled no-till or reduced-till agriculture that

65 helped to reduce soil erosion (Price et al. 2011). Due to the increasing

66 prevalence of herbicide resistant weeds farmers may return to deep tillage to

67 reduce weed pressures, which will hasten soil erosion (Price, et al. 2011).

68 To confound the above issues, the world population is expected to grow to

69 over nine billion by the year 2050 (Gerland et al. 2014). To feed this growing

70 population, it has been estimated that food production must increase by an

71 average of 44 million metric tons per year (Tester and Langridge 2010). In

72 addition, global warming due the release of $\mathrm{CO}_{2}$ from fossil fuels is posing

73 another threat (Anderson et al. 2016). To reduce this threat demand is increasing

74 for plant-based renewable feedstocks for the production of biofuels and

75 bioproducts (Ho et al. 2014). However, this leads to the concern that using

76 traditional crops for biofuel and bioproducts formation will threaten future food

77 security (Harvey and Pilgrim 2011). One solution is to intensify farmland output

78 (Tilman et al. 2011).

79 The deployment of cover crops during the fallow period between the

80 growth of summer crops can improve water quality and reduce the threat of

81 herbicide tolerant weeds (Dunn et al. 2016). However, traditional cover crops 
82 such as winter rye often need to be terminated before maturity to allow the

83 planting of summer crops (Roesch-McNally et al. 2017). Thus, such cover crops

84 do not enhance food or feedstock production. The winter annual weed,

85 pennycress (Thlaspi arvense L. also known as field pennycress and referred to

86 as "pennycress" hereafter), is being domesticated as a new alternative cover

87 crop (DeHaan et al. 2016, Isbell 2009, Jordan et al. 2007, Phippen and Phippen

88 2012, Sedbrook et al. 2014). As a winter cover, pennycress can utilize excess

89 nitrates before they escape into the environment and can suppress the growth of

90 spring weeds (Johnson et al. 2015, Johnson et al. 2017, Weyers et al. 201).

91 Importantly, pennycress can be harvested for its oilseeds (Fan et al. 2013, Moser

92 2012, Moser et al. 2009a, Moser et al. 2009b). Thus, pennycress has the

93 potential to intensify farm output by producing a new crop on land that is

94 temporally held fallow, such as much of the tens of million hectares of land

95 currently undergoing the corn/soybean rotation in the Midwestern United States

96 (Hart 2015).

97 The selection of pennycress as a target for domestication as a new cover

98 crop was based on positive natural traits such as extreme winter hardiness (-

$\left.9925^{\circ} \mathrm{C}\right)$, high seed yields for a wild species (1,000-2,000 kg/ha), and seeds rich in

100 oil (30-35\%) and protein (25-27\%) (Warwick et al. 2002). Pennycress produces

101 an oilseed suitable for making biofuels and bioproducts (Fan, et al. 2013, Moser

102 2012, Moser, et al. 2009a). However, the oil and associated seed meal are not

103 suitable for human or animal consumption. The oil is enriched with erucic acid,

104 which has been considered to be unsuitable for human consumption(Bell 1982).

105 In addition, the seeds contain glucosinolates, which are considered to be anti-

106 nutritional for humans and non-ruminant animals (Wittkop et al. 2009).

107 Furthermore, the mature seedpods are prone to breakage or shatter resulting in

108 pre-harvest seed loss. Lastly, in many regions, pennycress matures late enough

109 to cause delays in the planting of summer crops. Successful domestication of

110 pennycress requires the elimination of these negative traits.

111 Herein, we show that the rapid domestication of pennycress can be

112 facilitated by its close relationship to the model plant Arabidopsis (Sedbrook, et al. 
113 2014). Like Arabidopsis, pennycress is self-fertile and has a relatively small non-

114 repetitive diploid genome. Genome sequencing and analyses revealed a mostly

115 one-to-one functional correspondence between single Arabidopsis genes and

116 single pennycress ortholog genes (Chopra et al. 2018b, Dorn et al. 2013, Dorn et

117 al. 2015). Importantly and directly related to the domestication of pennycress,

118 recessive Arabidopsis mutants have been described that eliminate weedy and

119 other agronomically undesirable traits (Provart et al. 2015, Sedbrook, et al. 2014).

120 The goal of this study was to identify similar mutants in pennycress with traits

121 considered to be crucial to the domestication of any plant species (Abbo et al.

122 2014). Using classical mutagenesis, we describe the isolation and

123 characterization of pennycress mutations conferring crucial domestication traits

124 such as early flowering/maturity, reduced seedpod shatter, reduced

125 glucosinolates, and reduced erucic acid along with reduced polyunsaturated fatty

126 acids resulting in the creation of canola-like high oleic oil. The causative

127 mutations responsible for each of these traits were identified. These mutant

128 sequences were used to develop molecular markers that have been successfully

129 employed to stack all of the mutations into a single line.

\section{Results}

134 For pennycress to fit between the rotations of traditional summer crops it needs

135 to mature in the spring without disrupting the planting of the following summer

136 crop (De Bruin and Pedersen 2008). To identify Arabidopsis-like mutants that

137 flower and mature early, pools of mutagenized population of $\mathrm{M}_{2}$ seeds were

138 planted in the field space adjacent to the University of Minnesota St Paul campus

139 (Chopra, et al. 2018b). During the following spring, plants in the field that

140 flowered early were tagged and followed through to maturity. Sixty-one

141 independent isolates that flowered and matured early compared to the wild-type

142 were identified during the primary screen. Nineteen of the 61 early flowering

143 mutants were confirmed for the inheritance of earliness traits in the following

144 generation. We further focused our efforts on one line, A7-25, that flowered and 
145 began producing seedpods 10-14 days earlier than the wild-type (compare Figs.

146 1a, b). In another site-year in St. Paul, this mutant line matured approximately

147 one week ahead of the wild-type allowing an early harvest in the field conditions

148 while demonstrating normal plant stature and yield (Table. S1)

149 To test the hypothesis that the A7-25 mutant carried a mutation in a

150 previously characterized in Arabidopsis gene, whole-genome sequencing (WGS)

151 was performed. It was found that A7-25 contains a mutation in the candidate

152 pennycress ortholog of the Arabidopsis EARLY FLOWERING 6 (ELF6) (referred

153 to as Ta-ELF6-1 in Fig. 1c, and Data S1-3) (Jeong et al. 2009, Noh et al. 2004).

154 In Arabidopsis, ELF6 activity de-represses the expression of the floral inhibitor

155 FLOWERING LOCUS C (FLC) gene by removing methyl groups from lysine 27

156 of histone 3 proteins associated with the FLC locus (Crevillã@n et al. 2014). FLC

157 controls flowering time in pennycress(Dorn et al. 2017). The reduced

158 demethylase activity in elf6 mutants results in reduced FLC expression, which

159 hastens flowering. As shown in Fig. 1c and Data S3 the mutation in Ta-ELF6-1

160 results in the substitution of a tyrosine $(\mathrm{Y})$ residue for a conserved histidine $(\mathrm{H})$

161 (Noh, et al. 2004). This substitution is predicted to disrupt the formation of the

162 iron-binding site in the Jumonji $\mathrm{C}(\mathrm{JmjC})$ domain that is required for histone 3

163 demethylase activity in many plant species(Lu et al. 2008). To determine if the

164 early flowering phenotype in pennycress co-segregates with the mutation, an $\mathrm{F}_{2}$

165 population derived from a cross between the mutant and wild-type (Ames23761)

166 was characterized. Statistical analysis of each genotype class in the $F_{2}$

167 population showed that plants homozygous for the Ta-elf6-1 mutation flowered

168 earlier than either homozygous wild-type or heterozygous plants ( $p$-values

1690.0002 and 0.0021, respectively (Fig. 1d).

170 All studies with Arabidopsis on the effects of the elf6 mutation on FLC

171 expression have been under controlled growth conditions. To determine if a

172 similar phenomenon occurs in field grown pennycress, we analyzed the effect of

173 the mutation on pennycress FLC expression prior to vernalization in the fall. As

174 shown in (Fig. 1e), FLC expression was reduced by $30.5 \pm 0.09 \%$ in the early

175 flowering A7-25 line compared to the wild-type grown in the same trial. These 
176 results show that ELF6 functions the same under field conditions for pennycress

177 as under controlled growth conditions for Arabidopsis.

178
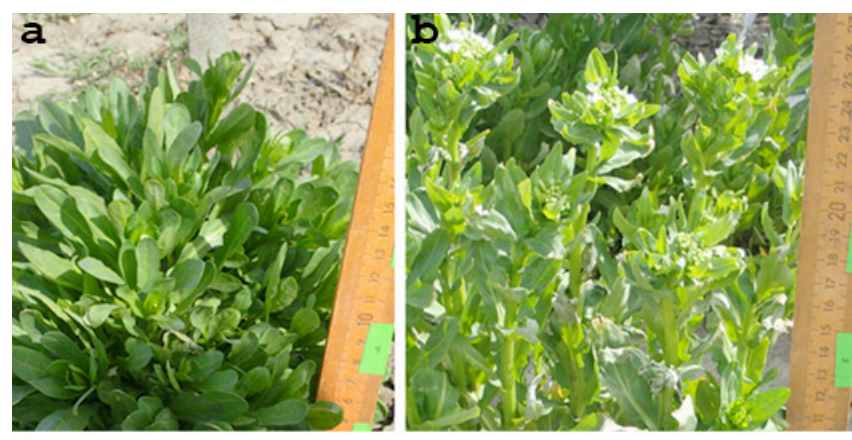

C

At_ELF6 DDIPGVTSPMVYIGMLFSWFAWHVEDHE

Ta_ELF6 DDIPGVTSPMVYIGMLFSWFAWHVEDHE

Ta_elf6-1 DDIPGVTSPMVYIGMLFSWFAWYVEDHE

OS_ELF6 DDVPGVTSPMVYIGMLFSWFAWHVEDHD

GM ELF6 DDIPGVTSPMVYIGMLFSWFAWHVEDHE

S1_ELF6 DDIPGVTSPMVYIGMLFSWFAWHVEDHE

d

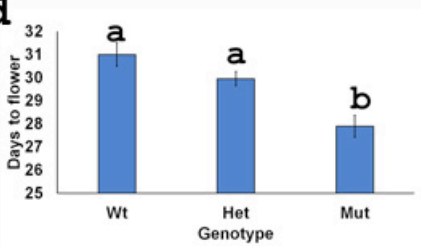

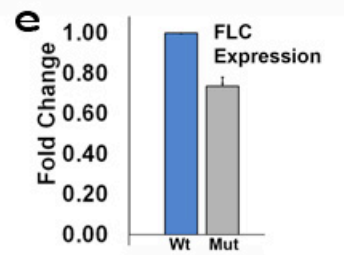

180 Figure. 1. Early flowering pennycress mutant. Images of field grown wild-type (a) and

181 early flowering Ta-elf6-1 mutant (b) plants taken on the same date. (c) Comparison of

182 amino acid sequences within the JmjC domain of ELF6-like genes highlighting the

183 residue altered in the pennycress mutant (red). (d) Average days to flowering in

184 greenhouse conditions for an $F_{2}$ population derived from a cross between wild-type and

185 Ta-elf6-1 plants. Allele-specific markers were used to assess the elf6-1 genotype of

186 members in the $F_{2}$ population. Note: Letters indicate significant differences based on

187 pair-wise Tukey test. (e) qPCR analysis of FLC expression in wild-type and early

188 flowering Ta-elf6-1 mutant plants using RNA from field grown plants collected in the fall

189 of 2017. FLC expression values were normalized using a ubiquitin probe (error bar

190 denotes standard deviation). Abbreviations: At - Arabidopsis thaliana, Os - Oryza sativa

191 (rice), Gm - Glycine max (soybean), SI-Solanum lycopersicum (tomato).

193 Reduced seedpod shatter pennycress

194 Pennycress seedpods exhibit premature breakage by wind or during mechanical

195 harvest resulting in yield losses of over $50 \%$. To identify pennycress mutants with 
196 reduced seedpod shatter, fields of $\mathrm{M}_{2}$ plants maintained past peak maturity were

197 screened for individuals exhibiting reductions in pod breakage or shatter

198 (compare Figs. 2a, b). Five individual recessive mutants have been identified,

199 along with a sixth line identified in a growth room screen, in which the trait

200 successfully passed through multiple generations.

201 Pennycress produces a flat circular seedpod called a silicle that has a

202 visibly distinct morphology compared to the long rod-shaped seedpods known as

203 siliques produced by Arabidopsis and other members of the Brassicaceae plant

204 family (Fig. 2c). Therefore, it was unknown if genes required for pod formation in

205 Arabidopsis would be the same as those controlling pod formation in pennycress.

206 To determine if the pennycress mutants contained mutations in genes known to

207 be associated with the formation of the separation zone in Arabidopsis, which

208 mediates pod breakage, the six lines were subjected to WGS. Three of the lines

209 were found to have mutations in the pennycress candidate ortholog of the

210 Arabidopsis INDEHISCENT (IND) gene (Fig. 2d, Data S1-3) (Liljegren et al.

211 2004). The analysis of the remaining three lines will be considered elsewhere.

212 IND encodes a $b H L H$ transcription factor that regulates the formation of

213 separation layers of cells contained within the value margin, which flanks the

214 septum (also called a replum) that divides the seedpod into to two halves

215 (Liljegren, et al. 2004). The Ta-ind-1 allele contains a mutation outside of a highly

216 conserved bHLH domain, while the Ta-ind-2 flanks this region and Ta-ind-3 has a

217 mutation in the conserved bHLH domain (Fig. 2d and Table S2). The seedpods

218 of both Ta-ind-2 and Ta-ind-3 failed to cleanly break on harvest signifying non-

219 functional dehiscence zones. However, Ta-ind-1 seedpods did break at the

220 septum to release seeds on harvest, but compared to wild-type, required more

221 force to break open the seedpods (Fig. 2d). As expected, Ta-ind-1 retains a

222 separation layer (Fig. 2e) that is not present in Ta-ind-2 or Ta-ind-3 (Fig. $2 \mathbf{f}$ and

223 Fig. S1). The finding of three independent pennycress ind alleles showing

224 reduced pod breakage strongly supports the causation of these mutations of the

225 observed phenotype. Of the three alleles, Ta-ind-1 should have the most 
226 agronomic utility, as the shatter-less phenotype of Ta-ind-2 and Ta-ind-3 reduces

227 seed harvestability with conventional combines.
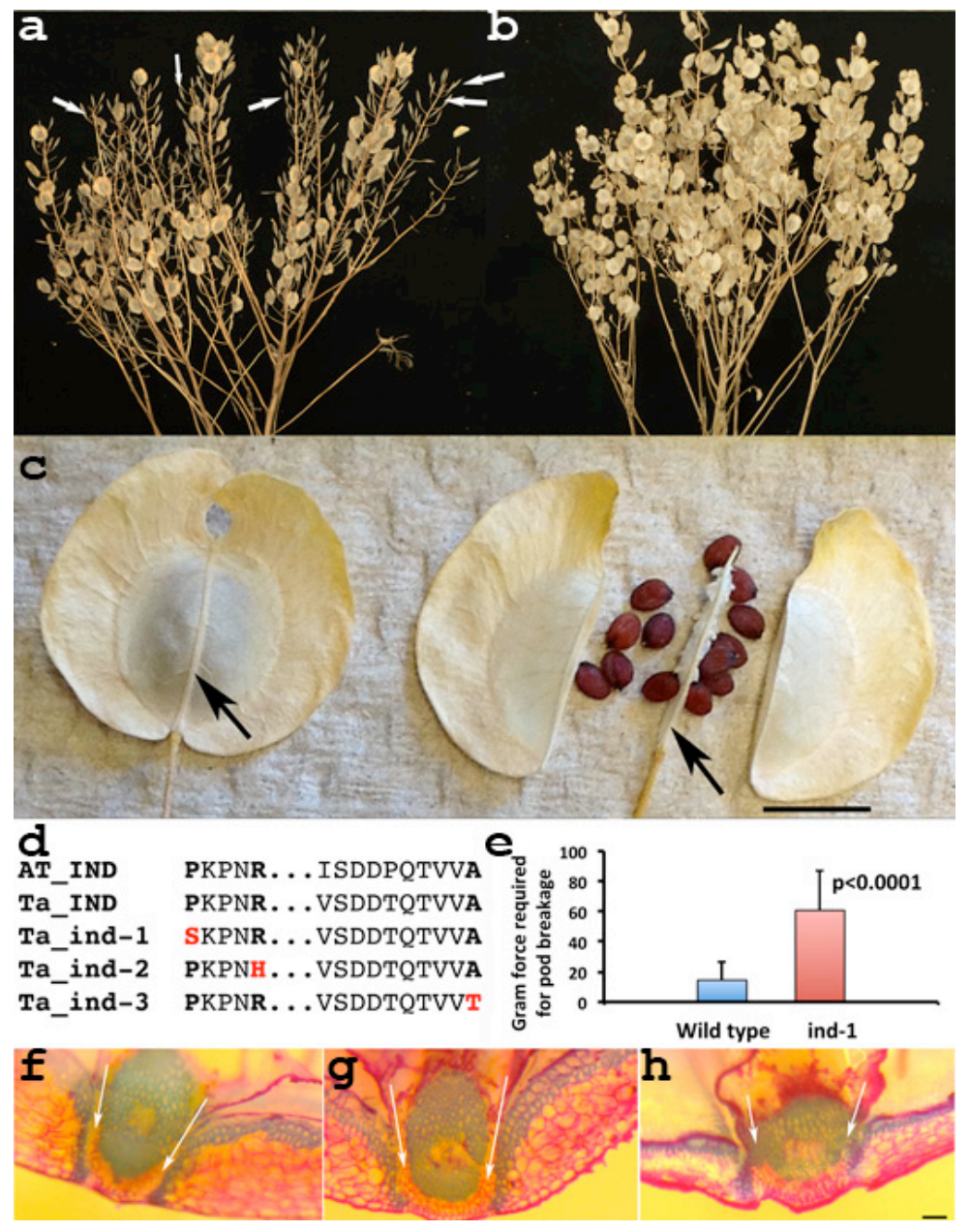

230 Figure 2. Isolation and characterization of pennycress seed pod mutants. (a) Field

231 grown wild-type plant compared to a reduced shatter mutant plant (b). (c) An intact

232 seedpod compared to a broken seedpod with released seeds (both are wild-type). The

233 arrows show the septum of an intact pod (left) and the septum structure that remains

234 after pod shatter. The arrows highlight the septum remaining after pod shatter.

235 (d) IND amino acid sequences derived from Arabidopsis (At-IND) and wild-type

236 pennycress (Ta-IND) compared to three mutant pennycress alleles (ind-1, ind-2 and ind-

237 3). The red letters highlight the amino acid substitutions. (e) Gram force needed to break

238 open pods from wild-type and ind-1 plants. Std. dev. error bars are shown. Freehand

239 sections through wild-type (e), ind-1 (f), and ind-2 (g) seedpods. The arrows highlight the

240 separation layers in wild-type and ind-1. This layer is missing in ind-2 and ind-3 (Fig. S2). 
241 The darker stained blue regions highlight lignified cell layers. The size bars in $\mathbf{c}$ and $\mathbf{h}$

242 represent $0.5 \mathrm{~cm}$ and $50 \mu \mathrm{m}$, respectively.

243

245 Low glucosinolate pennycress

$246 \quad$ Like Arabidopsis and other brassicas, pennycress seeds contain

247 glucosinolates ( $100 \mu \mathrm{mol} / \mathrm{g}$ of seeds), almost all in the form of sinigrin (Warwick,

248 et al. 2002). Most of the glucosinolates remain in the meal after the extraction of

249 oil from the seeds. This seed meal has added value if it can be used as an

250 animal feed supplement, however high amount of glucosinolates in the meal can

251 negatively affect animals (Wittkop, et al. 2009). Thus, a search for pennycress

252 lines with reduced glucosinolates was conducted. As described in a previous

253 report, 15,000 lines were scanned using Near Infra-Red Spectroscopy (NIRS) to

254 estimate seed composition traits in the intact seeds (Chopra et al. 2018a). The

255 analysis of these scans identified one line predicted to have very low

256 glucosinolate levels, which was confirmed via wet lab assays for total seed

257 glucosinolates (Fig. 3a). Interestingly, numerous individuals indicated that the

258 mutant seeds have a pleasant, nutty flavor that has not previously been reported

259 for seeds from plants in the Brassicaceae plant family. Seeds from the

260 Brassicaceae family typically are characterized to have flavors that range from

261 bitter, mustardy, garlicky, to hot. Hereafter, this pennycress mutant is referred to

262 as "nutty". The leaves of nutty also lacked the garlicky smell that accounts for

263 pennycress also being called "stinkweed".

264 In Arabidopsis, the biochemical pathway leading to the formation of

265 various glucosinolates including sinigrin has been well characterized(Sonderby et

266 al. 2010). Thus, we conducted WGS on nutty and searched for a mutation in a

267 gene known to be involved in glucosinolate biosynthesis in Arabidopsis. This led

268 to the identification of a pennycress mutation in a gene that is equally related to a

269 family of three tandemly linked genes in Arabidopsis called ALKENYL

270 HYDROXALKYL PRODUCING 1, 2, and 3 (AOP1,2,3)(Kliebenstein et al. 2001).

271 The analysis of an $\mathrm{F}_{2}$ from a cross between wild type and mutants showed that 
272 the reduced glucosinolate nutty phenotype was tightly linked to the mutation in

273 the AOP-like sequence (Fig. S2). HPLC analysis of glucosinolates from nutty

274 confirmed the reduction in sinigrin and also revealed a mild excess accumulation

275 of 3-methylsulfinylpropyl and 3-methylthiopropyl glucosinolates, which are

276 precursors to sinigrin in the biosynthetic pathway, supporting the hypothesis that

277 the pennycress AOP-like gene encodes an enzyme with Arabidopsis AOP2

278 alkenyl producing activity converting 3-methylsulfinylpropyl glucosinolate to

279 sinigrin (Fig. 3d) (Kliebenstein, et al. 2001). Thus, the mutant gene was named

280 Ta-aop2-1. Of note, all three glucosinolates shown in the HPLC profile shown in

281 Fig. 3c can be detected in the glucosinolate profile shown in Fig. 3a. If there was

282 a simple blockage in the pathway one would predict that the total levels of

283 glucosinolates would be the same in both mutant and wild type, however, there is

284 a clear reduction in glucosinolates in nutty. Additional work is needed to further

285 understand the molecular mechanisms responsible for the overall reduction in

286 glucosinolates in this mutant. 

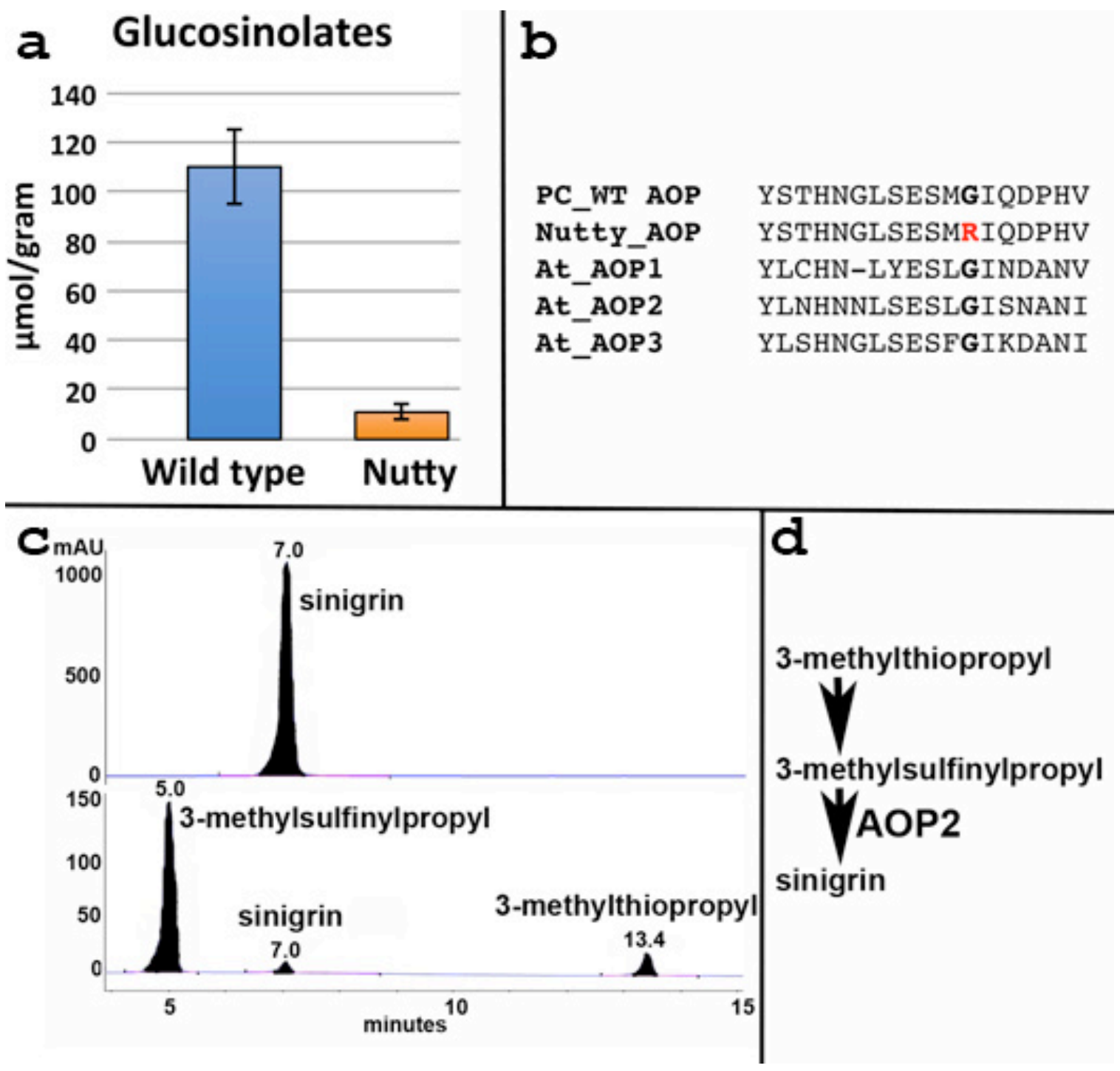

YSTHNGLSESMGIQDPHV YSTHNGLSESMRIQDPHV YLCHN-LYESLGINDANV YLNHNNLSESLGISNANI YLSHNGLSESFGIKDANI

Figure 3. Comparison of glucosinolates in wild-type and Nutty (aop2-1) mutant pennycress. (a) Spectrometric quantitation of total glucosinolates in wild-type and the nutty mutant. Error bars highlight Std. Dev. (b) AOP-like amino acid sequences derived from Arabidopsis (At-AOP 1 through 3) and wild-type pennycress AOP2 (PC_WT AOP) compared to the nutty mutant (Nutty-AOP). (c) HPLC analysis of desulfated glucosinolates from wild-type and the nutty mutant, top and bottom, respectively. Peaks are labeled with compound name and the time (minutes) of flow through the HPLC. (d) Terminal biochemical steps leading to the synthesis of the glucosinolate sinigrin. The step mediated by the enzyme encoded by $A O P 2$ in Arabidopsis is shown.

\section{Improving fatty acid composition of pennycress}


The fatty acid composition of pennycress oil is similar to that of rapeseed containing over 35\% erucic acid (Fig. 4a) (Claver et al. 2017, Moser, et al.

304 2009a). Oils containing such high levels of erucic acid are not considered fit for 305 human or animal consumption(Knutsen et al. 2016). Therefore, a search was 306 made for lines with reduced erucic acid. This search was aided by the knowledge 307 that in Arabidopsis and other species, the biosynthesis of erucic acid is mediated 308 by a single enzyme, FATTY ACID ELONGATION1 (FAE1), which in two steps 309 converts oleic acid with eighteen carbons and one double bond (18:1) to erucic 310 acid with twenty-two carbons and one double bond (22:1) (James et al. 1995). 311 Similar to the detection of glucosinolates, the quantity of erucic acid along with 312 other types of fatty acids can be estimated using NIRS(James, et al. 1995). Thus, 313 the same 15,000 NIRS scans that were used to identify the reduced 314 glucosinolate line were used to search for lines with reduced erucic acid. This 315 analysis identified two independent lines with greatly reduced erucic acid. These 316 results were verified via gas chromatography (GC), which showed that both lines 317 only contained trace levels of erucic acid (Fig. 4b). The candidate pennycress

318 FAE1 alleles in these reduced erucic acid lines were amplified via PCR and 319 sequenced. Both lines contained independent nonsense mutations leading to 320 premature stops in the predicted pennycress FAE1 protein sequences (Data S1321 3). These results were further confirmed by WGS of these lines. The finding of 322 two strong loss of function alleles for the candidate pennycress FAE1 ortholog 323 giving rise to the expected phenotypes strongly supports causation of the 324 mutations.

325 Pennycress fae 1 mutants contain the desired reduction in erucic acid and 326 a desirable elevation in oleic acid. They also accumulate higher levels of fatty 327 acid with extra double bonds referred to as polyunsaturated fatty acids (PUFAs). 328 In particular, linolenic acid with 3 double bonds (18:3) was elevated. This fatty 329 acid belongs to the omega3 class of fatty acids, which are associated with 330 reduced heart disease, reduced bone fracture risk, and in reduced childhood 331 obesity (Perng et al. 2014, Rajaram 2014). However for many applications, 332 PUFAs are not desirable as the extra double bonds reduce the stability of the oil, 
333 thus shortening the shelf life of the products that contain the oil (Gordon 2001).

334 Therefore, a search was made for lines containing reduced levels of PUFAs

335 using the same NIRS screen. We identified two mutants with predicted

336 reductions in both linoleic and linolenic acids. These reductions were verified

337 using GC analysis (Fig. 4c). Both lines contained similar levels of erucic acid as

338 the wild-type, but the reductions in PUFA were compensated for by an increase

339 in oleic acid. The fatty acid profiles of these two lines resembled those from

340 Arabidopsis reduced oleate desaturation1 (rod1) mutants(Lu et al. 2009). This

341 was confirmed via the PCR amplification and sequencing of the candidate

342 pennycress genes (Data S1-3). These results were further confirmed by WGS of

343 these lines.

344

345

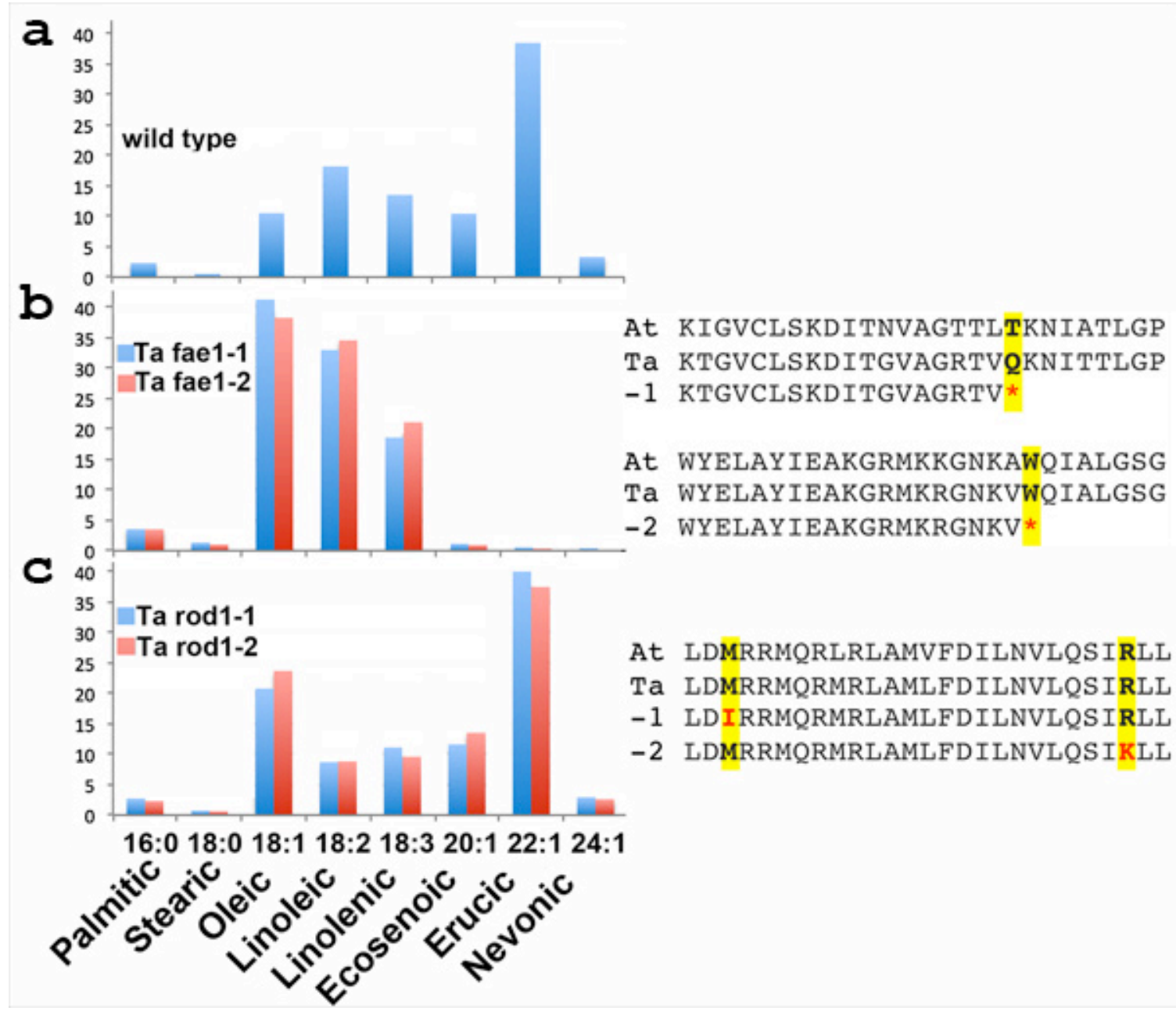



pennycress fae1 and rod1 mutant lines. (a-c) Profiles of wild-type pennycress, pennycress fae 1 and rod 1 mutants. The amino acid sequences derived from Arabidopsis and wild-type pennycress compared to mutant pennycress alleles are shown to the right. The red letters highlight the amino acid substitutions. Fatty acid

354 shown across the bottom.

\section{Stacking traits to develop domesticated pennycress}

This study has identified pennycress lines that harbor crucial domestication traits including early maturity, reduced shatter, reduced erucic acid and reduced PUFAs. Importantly, none of the described mutations reduced plant stature or predicted yield (Table S1 and Fig. S3). Knowledge of the causative mutations in each of the lines has been used to develop molecular probes that can follow each of the traits in segregating populations at the molecular level

363 (Table S3-4 and Data S1-3). To begin to combine these traits, a cross was made 364 between Ta-fae1-1 and Ta-rod1-1. KASP markers were designed for the specific 365 mutations in each of these mutants (see Materials and Methods). Using this approach (Fig S4) it was possible to identify the double mutants in an $F_{2}$ population at the seedling stage over two months before they began to produce seeds. The fatty acid composition of the oil from these double mutants was very high in oleic acid, low in erucic acid, with reduced levels of in PUFAs. Overall, the fatty acid profile of the double mutant pennycress oil closely resembled the profile of canola oil (compare Figs. 5a and 5b) (Dyer et al. 2008). Mutation specific KASP markers have been used to identify additional

373 double and triple mutant combinations in $F_{1}$ and $F_{2}$ individuals derived from 374 various crosses between the pennycress mutants (Table S5). This includes a 375 line that is homozygous for the combined Ta-fae-1, Ta-rod-1, and Ta-aop2-1 376 mutations. This line produces seeds that are essentially equivalent to those from 377 the so-called "double 0 " canola that similarly lack erucic acid and contain low 378 levels of glucosinolates(Bell 1982). Additional crosses have generated an $F_{1}$ 
379 plant that is heterozygous for all five of the desirable traits described in this report 380 (Fig S5). Progenies from this $F_{1}$ plant will be genotyped to identify a line

381 homozygous for all five mutations. This stacked line will represent the first-

382 generation domesticated pennycress variety and will be subjected to field-testing 383 ahead of potential commercialization.

384

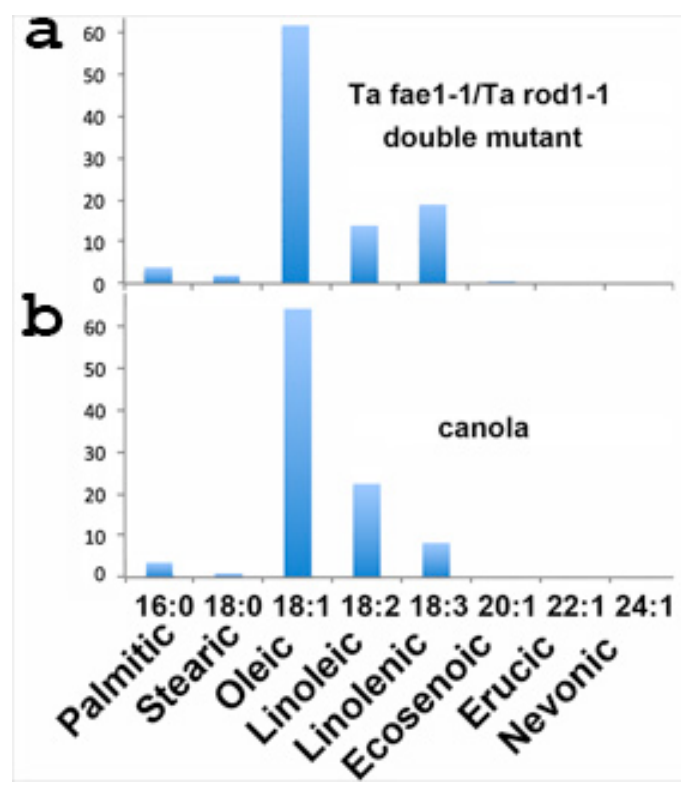

388 Figure 5. Comparison of fatty acid profiles of pennycress fae1/rod 1 double 389 mutant compared to canola oil. (a) Double mutant, (b) canola. Fatty acid 390 names along with carbon chain lengths and the degrees of desaturation are 391 shown across the bottom.

\section{Discussion}

The traits described in this report should allow domesticated pennycress to

398 intensify farm output by utilizing land from fall to spring that is not currently in

399 production. The early maturing pennycress described in this report will better fit 400 into existing crop rotations. The reductions in pod shatter will greatly improve 
401 harvestable yield, and the reductions in glucosinolates and improvements in oil

402 quality will enhance the value of the oilseeds. The rapid progress in identifying

403 these traits in pennycress was due to reduced gene redundancy, which facilitated

404 the creation of pennycress mutants that closely resemble similar Arabidopsis

405 mutants(Chopra, et al. 2018b, Sedbrook, et al. 2014).

406

The causative mutations responsible for the domestication traits described

408 in this study have been well studied in Arabidopsis(Provart, et al. 2015). Knowing

409 the causative nature of the mutations responsible for the pennycress

410 domestication traits is important for several reasons. The information can be

411 used to stimulate additional basic research on the molecular mechanisms that

412 control these traits. This is especially true for the Ta-AOP2 gene. The enzyme

413 encoded by this gene catalyzes the last step in the glucosinolate pathway in

414 pennycress. Through some unknown mechanism the mutation in this gene

415 results in reduced metabolic flux through the pathway. The information also can

416 be used to improve current crops or to help guide the domestication and creation

417 of new crops. For example, ELF6 now becomes good target for hastening

418 maturation of related $B$. napus (canola). Likewise these results show that

419 simultaneously reducing in both $R O D 1$ and $F A E 1$ activity can greatly increase

420 oleic acid content above that found for either of the single mutants. This should

421 have wide ranging applications in modifying the seed oil fatty acid content of

422 many plants. Importantly, the causative mutations can be used as molecular

423 markers as in the pipeline shown in Fig. $\mathbf{S 4}$ to combine the pennycress traits into

424 single lines. Using this pipeline, single plant lines harboring all the traits

425 described in this report will be ready for field-testing within the next two years.

426 The traits described in this report were created using classical

427 mutagenesis. Classical mutagenesis has long been used to induce useful

428 mutations in crop plants (Ahloowalia et al. 2004, Oladosu et al. 2016). For this

429 work we used EMS as a mutagen (Chopra, et al. 2018b). Treatments with EMS

430 generate up to thousands of mutations in each mutagenized line creating a large

431 pool of mutant genes in a relatively small population. This increases the odds of 
432 finding mutants of interest as described in this study. As previously described,

433 these pools mutations can be used to mine for additional desirable traits (Chopra,

434 et al. 2018b). On the downside these lines may carry deleterious mutations.

435 However, many of these can be identified from their known affects in Arabidopsis

436 and can be removed by marker-assisted breeding(Chopra, et al. 2018b).

437 In theory, it would have been faster to use gene-editing approaches to

438 create the domestication traits described in this report. In fact, we have created

439 an alternative zero erucic acid pennycress line using CRISPR-Cas9 mediated

440 gene editing (McGinn et al. 2018). However, successful utilization of gene editing

441 requires precise knowledge about the genes one wishes to target. This

442 knowledge is not always available. For example, ELF6, ROD1 and AOP2-like

443 were not on the original list of gene targets for improving pennycress(Sedbrook,

444 et al. 2014). Furthermore, the creation of partial loss of function mutations, such

445 as that responsible for the desirable Ta-ind-1 allele, requires prior knowledge

446 before gene editing can be employed. To balance speed and discovery, we will

447 continue to utilize both classical breeding to stack desirable traits and gene

448 editing to produce desirable mutations in existing elite pennycress breeding lines.

449 There are many obvious improvements that can be made to enhance the

450 potential success of pennycress as a new crop. For example, the dark colored

451 seed coats contain high levels of oxidized tannins, which can interfere with

452 protein uptake in the intestinal tracts of animals that are fed pennycress seed

453 meal(Butler 1992). In a previous report, pennycress mutants lacking tannins have

454 been described, and this trait is currently being added to the stacked line(Chopra,

455 et al. 2018b). Additional screens are underway to identify second-generation

456 domestication traits such as reduced seed dormancy, increased yield, increased

457 seed size, increased oil content and improved protein quality. Many of these

458 traits will aid in crop establishment and improve upon current net-economic

459 returns, which increase the likelihood that pennycress will be adopted (Ott et al.

460 2019).

461 The identification and stacking of domestication traits represent the first

462 step toward the creation a new crop. Concurrently with the ongoing work 
463 described in this report, agronomists and ecologists are working to develop

464 planting recommendations and to understand the effects of growing pennycress

465 on the landscape. In addition, food scientists are beginning to study the potential

466 of pennycress as a new food source for human consumption. For example, the

467 "double zero" - like pennycress seeds lacking erucic acid with greatly reduced

468 glucosinolate will be used for various analyses including feeding trials. The

469 canola-like oil will also provide an important new feedstock for the development

470 biofuels and bioproducts.

$471 \quad$ Newly domesticated pennycress has the potential to intensify farm output

472 by being grown during the fallow period between existing summer crops.

473 Importantly, pennycress grown during the fallow seasons has been shown to

474 provide much needed ecosystem services including nitrogen uptake and the

475 suppression of spring weeds, which will enhance the sustainability of current

476 agricultural practices. We believe the combined oilseed production and

477 ecosystem rewards will greatly outweigh the remaining challenges in developing

478 pennycress as a new cash cover crop.

479

480 


\section{Materials and Methods}

482

\section{Screening of mutant pennycress populations for important traits}

We previously described the creation of a large pennycress mutant populations using ethyl methane sulfonate (EMS) and other mutagens (Chopra, et al. 2018b). These represent the test populations used to search for pennycress mutants similar to Arabidopsis mutants that exhibit agronomically desirable phenotypes.

\section{Seed Source, DNA isolation, Sanger Sequencing, Whole-Genome}

\section{Sequencing}

The source of the pennycress seeds for development of genomic resources was previously described in Dorn et al. (Dorn, et al. 2015). Mutants characterized in this report were derived from EMS treated seeds as described in Chopra et al.(Chopra, et al. 2018b). DNA was isolated from the candidate mutants using a Qiagen plant genomic DNA kit (Qiagen, Valencia, CA). DNA was subjected to WGS using an Illumina HiSeq 2500 sequencer (2x125 bp). Raw reads were analyzed using the method described by Chopra et al.(Chopra, et al. $2018 \mathrm{~b})$ to detect and predict the nature of mutations in each of these candidate mutants (Table S3). Gene-specific primers (Table S6) were designed to PCR amplify and sequence putative pennycress orthologs. PCR products were

503 Genomics Workbench (Qiagen, Valencia, CA) to process files, identify and

504 confirm the corresponding mutations. Protein sequence alignments were

505 performed using the sequences from Thlaspi arvense (Ta), and Arabidopsis

506 thaliana (At) for the candidate genes. Mutation sites of the candidate genes were 507 changed manually, and alignments were performed using the clustalW program.

508 Genomic DNA sequences, protein sequences and alignments for all the wild-type 509 and mutants genes discussed in this article are provided in the Data S1, S2, and 510 S3 files. 


\section{Early flowering phenotyping}

$513 \quad F_{2}$ plants from a cross between the wild-type GRIN accession Ames

51423761 and the early flowering mutant MN A7-25 were planted into Ray Leach

515 SC10 Cone-tainers $^{\mathrm{TM}}$ filled with Sun Gro Metro Mix 560 Sun-Coir. After

516 germination, plants were allowed to grow to the two true leaf stage in a $20^{\circ} \mathrm{C}$

517 growth chamber. Plants were then transferred to a growth chamber maintained at

$5184{ }^{\circ} \mathrm{C}$ and 8 hours of light for a vernalization period of 21 days. After this period

519 plants were returned to the $20^{\circ} \mathrm{C}$ growth chamber. Days to flowering were

520 recorded as the number of days after plants were returned to the $20^{\circ} \mathrm{C}$ growth

521 chamber to the first open florets visible on the plant.

\section{Genotyping using allele-specific markers}

524 To perform co-segregation analysis on $F_{2}$ progenies derived from elf6-

$5251^{*}$ Ames23761 and aop2-like-1*MN106 crosses, we designed allele-specific and

526 flanking primers for each of the alleles (Table S4). DNA was extracted using the

527 Sigma ready extract method and genotyping was performed using the methods

528 described in Chopra et al. (Chopra, et al. 2018b).

Expression analysis

531 Leaf tissue from ten seedlings for each replicate were pooled from wild-

532 type and the mutant (elf6-1) for RNA extractions. RNA was extracted using the

533 RNAeasy mini clean up kit (Qiagen, Valencia, CA) and treated with turbo DNase

534 (ThermoFisher Cat. No. AM2238). To evaluate the expression patterns in the

535 wild type and mutants; qRT-PCR primers were designed for actin, tubulin, ELF6

536 and FLC genes (Table S7). Briefly, cDNA libraries were synthesized using

537 Invitrogen cDNA synthesis kit (Invitrogen, Grand Island, NY) and PCR was

538 performed using SybrGreen (Roche Cat. No. 04707516 001) on a LightCycler

539480 (Roche, Basel Switzerland). Average $C_{t}$ values generated from three

540 replicates for each of the cDNA libraries were used to normalize and calculate

541 the fold change in expression of genes, respectively. 


\section{Reduced pod shatter phenotyping}

$544 \quad$ The force required to break apart seedpods at the septum was determined

545 using a gram force tension gauge (SSEYL ATG-100-2 Tension Gauge) attached

546 to a two-inch alligator clip (Gardner Bender, Milwaukee, WI). Briefly, one side of

547 a pod was clipped and then the other side was manually pulled until either the

548 pod broke at the septum or the fin tore. Pods that broke on handling before being

549 clipped were recorded as zero. For each line, ten pods each from five different

550 plants were used for the measurements.

551 Samples for observations of separation layers were prepared by either free-hand

552 or microtome sectioning. The free-hand sections were cut with a razor blade,

553 briefly stained with $0.05 \%$ toluidine blue $\mathrm{O}$, and then transferred to a microscope

554 slide for observation using Nikon SMZ1500 stereo microscope. Samples used for

555 microtome sectioning were fixed for $5 \mathrm{~h}$ in $2 \%$ glutaraldehyde buffered with

$5560.025 \mathrm{M}$ phosphate buffer, $\mathrm{pH} 7$, and post-fixed $1-2 \mathrm{~h}$ in $2 \%$ OsO4. Specimens

557 were dehydrated in a graded series of acetone, infiltrated in Spurr's resin, and

558 polymerized in a $70^{\circ} \mathrm{C}$ oven. Semi-thin sections $1 \mu \mathrm{m}$ thick were made with a

559 Leica UCT Ultracut Microtome, stained with $0.1 \%$ toluidine blue, and viewed with

560 a Leica DMRBE compound microscope using the 20x objective.

561

562 Glucosinolates in leaf tissue and seeds using UV absorbance method

563 To determine glucosinolate content in the pennycress leaf tissues and

564 pennycress seeds, we recorded the fresh tissue weights or seed weights of the

565 samples. Briefly, glucosinolates were extracted in $80 \%$ methanol followed by

566 purification and were quantified using the method described by Chopra et al.

567 (Chopra, et al. 2018a). At least three biological replicates were used for

568 estimating the glucosinolate content in each of the segregating progeny.

569

570 HPLC analysis of wild-type and Nutty seeds

$571 \quad$ Glucosinolates in the seeds of the wild-type and mutant samples were

572 extracted and analyzed with HPLC using the method described by Kliebenstein

573 et al. (Kliebenstein, et al. 2001). Briefly, forty microliters of the glucosinolate 
574 extract was run on a 5-mm column (Lichrocart 250-4 RP18e, Hewlett-Packard,

575 Waldbronn, Germany) on a Hewlett-Packard 1100 series HPLC. Compounds

576 were detected at $229 \mathrm{~nm}$ and separated utilizing the programs described by

577 Kliebenstein et al.(Kliebenstein, et al. 2001) with aqueous acetonitrile.

578

579 Fatty acid composition analysis using Gas Chromatography

580 Approximately $100 \mathrm{mg}$ of seeds from the wild-type and mutants of interest

581 from NIRS scans were weighed and crushed with 1,000 $\mu \mathrm{l}$ of hexane containing

582 a C17:0 internal standard using a mechanical homogenizer for three min at 10

$583 \mathrm{~m} / \mathrm{s}$. The hexane supernatant containing the extracted oil was then transferred to

584 glass vials for methylation and FAMES were separated and detected using the

585 methods described in Chopra et al (Chopra, et al. 2018a). At least two replicates

586 were used for estimating the fatty acid composition in each of the lines. 


\section{Acknowledgments}

591

General: We acknowledge the hard work of many undergraduates and others who contributed to this study including: Karl Nord, Carl Branch, Liam Sullivan, Luke Aldrich,

593 Greta Rockstad and many others. We thank Martha Cook and Tara Nazarenus for help

594 with tissue embedding / sectioning / microscopy and seed oil analyses, respectively.

596 Funding: This material is based upon work that is supported by the National Institute of

597 Food and Agriculture, U.S. Department of Agriculture, under award numbers 2014-

598 67009-22305 and 2018-67009-27374 to M.D.M, J.C.S and W.B.P. Funding for research

599 conducted in the E.B.C lab was provided by U.S. Department of Energy, Office of

600 Science, OBER (DOE-BER SC0012459) and NSF Plant Genome Program (13-39385).

601 Additional funds were provided by the Minnesota Department of Agriculture and the

602 University of Minnesota Forever Green Initiative to J.A.A. and B.I., and the Walton

603 Family Foundation, PepsiCo and General Mills to D.L.W.

604

605 Author Contributions M.D.M. and J.C.S. conceived the study, designed experiments,

606 supervised and organized coworkers, created mutagenized populations, isolated

607 mutants, helped characterize the mutants, identified candidate genes, and co-wrote the

608 manuscript. R.C. along with E.B.C, C.G. and B.I. characterized the fatty acid profiles,

609 along with K.M.D. performed WGS analyses, and also independently performed

610 extensive data analyses and helped write the first draft of the manuscript. J.L. D.J.K, and

611 T.U. were responsible for the wet lab glucosinolate analyses. E.D., N.F, R.E, M.E., M.M.,

612 A.B. and K.A. isolated mutants and helped characterize candidate genes. M.O. helped

613 evaluate FLC expression and seed yield of the elf6 mutant. J.A.A. and K.A. help with the

614 initial NIR set-up. K.M.D, K.F. and R.C. helped characterize the elf6 mutant. A.B.

615 generated and imaged wild-type and ind-3 seedpod sections. D.L.W. isolated wild-type

616 line MN106 used in the study and aided in planning.

618 Competing Interests: The authors declare potential competing financial interests as

619 intellectual property applications have been submitted on portions of the reported

620 research. 
bioRxiv preprint doi: https://doi.org/10.1101/609990; this version posted April 16, 2019. The copyright holder for this preprint (which was not certified by peer review) is the author/funder, who has granted bioRxiv a license to display the preprint in perpetuity. It is made available under aCC-BY-NC-ND 4.0 International license.

622 Data and materials availability: All sequence information described in this study is

623 contained within the Supplementary Materials. All plant materials described in this report

624 are available upon completion of Material Transfer Agreements.

625

626 
(2014) Yield Gains in Major U.S. Field Crops Madison, WI: American Society of Agronomy, Inc., Crop Science Society of America, Inc., and Soil Science Society of America, Inc.

Abbo, S., Pinhasi van-Oss, R., Gopher, A., Saranga, Y., Ofner, I. and Peleg, Z. (2014) Plant domestication versus crop evolution: a conceptual framework for cereals and grain legumes. Trends Plant Sci, 19, 351-360.

Ahloowalia, B.S., Maluszynski, M. and Nichterlein, K. (2004) Global impact of mutation-derived varieties. Euphytica, 135, 187-204.

Anderson, T.R., Hawkins, E. and Jones, P.D. (2016) CO2, the greenhouse effect and global warming: from the pioneering work of Arrhenius and Callendar to today's Earth System Models. Endeavour, 40, 178-187.

Bell, J. (1982) From rapeseed to canola: A brief history of research for superior meal and edible oil. Poultry Sci, 61, 613-622.

Butler, L.G. (1992) Antinutritional Effects of Condensed and Hydrolyzable Tannins. In Plant Polyphenols: Synthesis, Properties, Significance (Hemingway, R.W. and Laks, P.E. eds). Boston, MA: Springer US, pp. 693-698.

Chopra, R., Folstad, N., Lyons, J., Ulmasov, T., Gallaher, C., Sullivan, L., McGovern, A., Mitacek, R., Frels, K., Altendorf, K., Killiam, A., Ismail, B., Anderson, J.A., Wyse, D.L. and Marks, M.D. (2018a) The Adaptable Use of Brassica NIRS Calibration Equations to Identify Pennycress Variants to Facilitate the Rapid Domestication of a New Winter Oilseed Crop. in press.

Chopra, R., Johnson, E.B., Daniels, E., McGinn, M., Dorn, K.M., Esfahanian, M., Folstad, N., Amundson, K., Altendorf, K., Betts, K., Frels, K., Anderson, J.A., Wyse, D.L., Sedbrook, J.C. and Marks, M.D. (2018b) Translational genomics using Arabidopsis as a model enables the characterization of pennycress genes through forward and reverse genetics. The Plant Journal, 96, 1093-1105.

Claver, A., Rey, R., López, M.V., Picorel, R. and Alfonso, M. (2017) Identification of target genes and processes involved in erucic acid accumulation during seed development in the biodiesel feedstock Pennycress (Thlaspi arvense L.). J Plant Physiol, 208, 7-16.

Crevillã̊n, P., Yang, H., Cui, X., Greeff, C., Trick, M., Qiu, Q., Cao, X. and Dean, C. (2014) Epigenetic reprogramming that prevents transgenerational inheritance of the vernalized state. Nature, 515, 587.

De Bruin, J.L. and Pedersen, P. (2008) Soybean Seed Yield Response to Planting Date and Seeding Rate in the Upper Midwest All rights reserved. No part of this periodical may be reproduced or transmitted in any form or by any means, electronic or mechanical, including photocopying, recording, or any information storage and retrieval system, without permission in writing from the publisher. Agron J, 100, 696-703.

DeHaan, L.R., Van Tassel, D.L., Anderson, J.A., Asselin, S.R., Barnes, R., Baute, G.J., Cattani, D.J., Culman, S.W., Dorn, K.M. and Hulke, B.S. (2016) A pipeline strategy for grain crop domestication. Crop Sci, 56, 917-930.

Dorn, K.M., Fankhauser, J.D., Wyse, D.L. and Marks, M.D. (2013) De novo assembly of the pennycress (Thlaspi arvense) transcriptome provides tools for the development of a winter cover crop and biodiesel feedstock. Plant Journal, 75, 1028-1038.

Dorn, K.M., Fankhauser, J.D., Wyse, D.L. and Marks, M.D. (2015) A draft genome of field pennycress (Thlaspi arvense) provides tools for the domestication of a new winter biofuel crop. DNA Research, 22, 121-131.

Dorn, K.M., Johnson, E.B., Daniels, E., Wyse, D. and Marks, M.D. (2017) Spring flowering habit in field pennycress (Thlaspi arvense) has arisen multiple independent times. Plant Direct, 2, e00097.

Dunn, M., Ulrich-Schad, J.D., Prokopy, L.S., Myers, R.L., Watts, C.R. and Scanlon, K. (2016) Perceptions and use of cover crops among early adopters: Findings from a national survey. Journal of Soil and Water Conservation, 71, 29-40.

Dyer, J.M., Stymne, S., Green, A.G. and Carlsson, A.S. (2008) High-value oils from plants. The Plant Journal, 54, 640-655.

Fan, J., Shonnard, D.R., Kalnes, T.N., Johnsen, P.B. and Rao, S. (2013) A life cycle assessment of pennycress (Thlaspi arvense L.)-derived jet fuel and diesel. Biomass and Bioenergy, 55, 87-100. 
683

684

685

686

687

688

689

690

691

692

693

694

695

696

697

698

699

700

701

702

703

704

705

706

707

708

709

710

711

712

713

714

715

716

717

718

719

720

721

722

723

724

725

726

727

728

729

730

731

732

733

734

735

736

737

Gerland, P., Raftery, A.E., Ševčíková, H., Li, N., Gu, D., Spoorenberg, T., Alkema, L., Fosdick, B.K., Chunn, J., Lalic, N., Bay, G., Buettner, T., Heilig, G.K. and Wilmoth, J. (2014) World population stabilization unlikely this century. Science, 346, 234-237.

Gordon, M.H. (2001) The development of oxidative rancidity in foods. In Antioxidants in food: Elsevier, pp. 7-21.

Hart, G.E. (2015) Feeding the ethanol boom: Where will the corn come from. Iowa Ag Review, 12.

Harvey, M. and Pilgrim, S. (2011) The new competition for land: Food, energy, and climate change. Food Policy, 36, S40-S51.

Heap, I. (2014) Herbicide Resistant Weeds. In Integrated Pest Management: Pesticide Problems, Vol.3 (Pimentel, D. and Peshin, R. eds). Dordrecht: Springer Netherlands, pp. 281-301.

Ho, D.P., Ngo, H.H. and Guo, W. (2014) A mini review on renewable sources for biofuel. Bioresource Technology, 169, 742-749.

Isbell, T.A. (2009) US effort in the development of new crops (Lesquerella, Pennycress Coriander and Cuphea). Oléagineux, Corps gras, Lipides, 16, 205-210.

James, D.W., Jr., Lim, E., Keller, J., Plooy, I., Ralston, E. and Dooner, H.K. (1995) Directed tagging of the Arabidopsis FATTY ACID ELONGATION1 (FAE1) gene with the maize transposon activator. Plant Cell, 7, 309-319.

Jeong, J.H., Song, H.R., Ko, J.H., Jeong, Y.M., Kwon, Y.E., Seol, J.H., Amasino, R.M., Noh, B. and Noh, Y.S. (2009) Repression of FLOWERING LOCUS T chromatin by functionally redundant histone $\mathrm{H} 3$ lysine 4 demethylases in Arabidopsis. PLoS One, 4, e8033.

Johnson, G.A., Kantar, K.B., Betts, K.J. and Wyse, D.L. (2015) Field Pennycress Production and Weed Control in a Double Crop System with Soybean in Minnesota. Agron J, 107, 532-540.

Johnson, G.A., Wells, M.S., Anderson, K., Gesch, R.W., Forcella, F. and Wyse, D.L. (2017) Yield Tradeoffs and Nitrogen between Pennycress, Camelina, and Soybean in Relay- and Double-Crop Systems. Agron J, 109, 2128-2135.

Jordan, N., Boody, G., Broussard, W., Glover, J.D., Keeney, D., McCown, B.H., McIsaac, G., Muller, M., Murray, H., Neal, J., Pansing, C., Turner, R.E., Warner, K. and Wyse, D. (2007) Environment - Sustainable development of the agricultural bio-economy. Science, 316, 1570-1571.

Kliebenstein, D.J., Lambrix Vm Fau - Reichelt, M., Reichelt M Fau - Gershenzon, J., Gershenzon J Fau - Mitchell-Olds, T. and Mitchell-Olds, T. (2001) Gene duplication in the diversification of secondary metabolism: tandem 2-oxoglutarate-dependent dioxygenases control glucosinolate biosynthesis in Arabidopsis. Plant Cell, 13 (3), 681-693.

Knutsen, H.K., Alexander, J., BarregAard, L., Bignami, M., Brüschweiler, B., Ceccatelli, S., Dinovi, M., Edler, L., Grasl - Kraupp, B. and Hogstrand, C. (2016) Erucic acid in feed and food. EFSA Journal, 14, 1-173.

Liljegren, S.J., Roeder, A.H., Kempin, S.A., Gremski, K., Ostergaard, L., Guimil, S., Reyes, D.K. and Yanofsky, M.F. (2004) Control of fruit patterning in Arabidopsis by INDEHISCENT. Cell, 116, 843-853.

Lu, C., Xin, Z., Ren, Z., Miquel, M. and Browse, J. (2009) An enzyme regulating triacylglycerol composition is encoded by the ROD1 gene of Arabidopsis. Proc Natl Acad Sci U S A, 106, 18837 18842.

Lu, F., Li, G., Cui, X., Liu, C., Wang, X.-J. and Cao, X. (2008) Comparative Analysis of JmjC Domaincontaining Proteins Reveals the Potential Histone Demethylases in Arabidopsis and Rice. J Integr Plant Biol, 50, 886-896.

McGinn, M., Phippen, W.B., Chopra, R., Bansal, S., Jarvis, B.A., Phippen, M.E., Dorn, K.M., Esfahanian, M., Nazarenus, T.J., Cahoon, E.B., Durrett, T.P., Marks, M.D. and Sedbrook, J.C. (2018) Molecular tools enabling pennycress (Thlaspi arvense) as a model plant and oilseed cash cover crop. Plant Biotechnol J, 0.

Moser, B.R. (2012) Biodiesel from alternative oilseed feedstocks: camelina and field pennycress. Biofuels, 3, 193-209.

Moser, B.R., Knothe, G., Vaughn, S.F. and Isbell, T.A. (2009a) Production and Evaluation of Biodiesel from Field Pennycress (Thlaspi arvense L.) Oil. Energ Fuel, 23, 4149-4155.

Moser, B.R., Shah, S.N., Winkler-Moser, J.K., Vaughn, S.F. and Evangelista, R.L. (2009b) Composition and physical properties of cress (Lepidium sativum L.) and field pennycress (Thlaspi arvense L.) oils. Ind Crop Prod, 30, 199-205. 
Noh, B., Lee, S.H., Kim, H.J., Yi, G., Shin, E.A., Lee, M., Jung, K.J., Doyle, M.R., Amasino, R.M. and Noh, Y.S. (2004) Divergent roles of a pair of homologous jumonji/zinc-finger-class transcription factor proteins in the regulation of Arabidopsis flowering time. Plant Cell, 16, 2601-2613.

Oladosu, Y., Rafii, M.Y., Abdullah, N., Hussin, G., Ramli, A., Rahim, H.A., Miah, G. and Usman, M. (2016) Principle and application of plant mutagenesis in crop improvement: a review. Biotechnology \& Biotechnological Equipment, 30, 1-16.

Ott, M.A., Eberle, C.D., Thom, M.D., Archer, D.W., Forcella, F., Gesch, R.W. and Wyse, D.L. (2019) Economics and agronomics of dual-cropping pennycress and camelina with soybean in Minnesota. Agron $J$, in press.

Perng, W., Villamor, E., Mora-Plazas, M., Marin, C. and Baylin, A. (2014) Alpha-linolenic acid (ALA) is inversely related to development of adiposity in school-age children. European Journal Of Clinical Nutrition, 69, 167.

Phippen, W.B. and Phippen, M.E. (2012) Soybean Seed Yield and Quality as a Response to Field Pennycress Residue. Crop Sci, 52, 2767-2773.

Price, A.J., Balkcom, K.S., Culpepper, S.A., Kelton, J.A., Nichols, R.L. and Schomberg, H. (2011) Glyphosate-resistant Palmer amaranth: A threat to conservation tillage. Journal of Soil and Water Conservation, 66, 265-275.

Provart, N.J., Alonso, J., Assmann, S.M., Bergmann, D., Brady, S.M., Brkljacic, J., Browse, J., Chapple, C., Colot, V., Cutler, S., Dangl, J., Ehrhardt, D., Friesner, J.D., Frommer, W.B., Grotewold, E., Meyerowitz, E., Nemhauser, J., Nordborg, M., Pikaard, C., Shanklin, J., Somerville, C., Stitt, M., Torii, K.U., Waese, J., Wagner, D. and McCourt, P. (2015) 50 years of Arabidopsis research: highlights and future directions. New Phytol., 209, 921-944.

Rajaram, S. (2014) Health benefits of plant-derived $\hat{\mathrm{I}} \pm$-linolenic acid. Am J Clin Nutr, 100, 443S-448S.

Robertson, G.P. and Vitousek, P.M. (2009) Nitrogen in Agriculture: Balancing the Cost of an Essential Resource. Annual Review of Environment and Resources, 34, 97-125.

Roesch-McNally, G.E., Basche, A.D., Arbuckle, J.G., Tyndall, J.C., Miguez, F.E., Bowman, T. and Clay, R. (2017) The trouble with cover crops: Farmers' experiences with overcoming barriers to adoption. Renew Agr Food Syst, 33, 322-333.

Sedbrook, J.C., Phippen, W.B. and Marks, M.D. (2014) New approaches to facilitate rapid domestication of a wild plant to an oilseed crop: example pennycress (Thlaspi arvense L.). Plant Sci, 227, 122-132.

Sonderby, I.E., Geu-Flores, F. and Halkier, B.A. (2010) Biosynthesis of glucosinolates--gene discovery and beyond. Trends Plant Sci, 15, 283-290.

Tester, M. and Langridge, P. (2010) Breeding Technologies to Increase Crop Production in a Changing World. Science, 327, 818 .

Tilman, D., Balzer, C., Hill, J. and Befort, B.L. (2011) Global food demand and the sustainable intensification of agriculture. Proceedings of the National Academy of Sciences, 108, 20260.

Warwick, S.I., Francis, A. and Susko, D.J. (2002) The biology of Canadian weeds. 9. Thlaspi arvense L. (updated). Can J Plant Sci, 82, 803-823.

Weyers, S., Thom, M.D., Forcella, F., Eberle, C.A., Matthees, H., Gesch, R., Ott, M.A., Feyereisen, G., Strock, J.S. and Wyse, D. (201) Reduced-nutrient leachates in cash cover crop-soybean systems. $J$ Environ Qual, in press.

Wittkop, B., Snowdon, R.J. and Friedt, W. (2009) Status and perspectives of breeding for enhanced yield and quality of oilseed crops for Europe. Euphytica, 170, 131.

Wortmann, C.S., Tarkalson, D.D., Shapiro, C.A., Dobermann, A.R., Ferguson, R.B., Hergert, G.W. and Walters, D. (2011) Nitrogen Use Efficiency of Irrigated Corn for Three Cropping Systems in Nebraska. Agron J, 103, 76-84. 
790 List

791 Figure S1. Comparisons of the separation layer of wild-type Spring 32 (left) and

792 ind-3 (right) seedpod sections stained with toluidine blue.

793 Figure S2. Average glucosinolate content of the progenies from the segregating 794 population of Ta-aop2-1 plants.

795 Figure S3. Comparisons of a wild-type pennycress plant with the "Nutty" aop2-1

796 and "canola-like-oil" fae1-1 rod1-1 mutants grown in controlled chambers.

797 Figure S4. A schematic representation of pennycress life-cycle from seeds to a 798 mature plant.

799 Figure S5. F1 plant carrying all of the described mutations in this report and was 800 selected using the allele-specific primers and strategy described in Fig S4.

801 Table S1. Plant height and seed yield comparisons between wild-type and early 802 flowering mutant (elf6-1) grown in $1 \times 1 \mathrm{~m}$ plots in the field.

803 Table S2. Protein domain analysis to highlight the conserved region in the 804 Indehiscent gene (IND) using several databases.

805 Table S3. Summary of the mutations in the domestication related genes 806 characterized in this study.

807 Table S4. Allele-specific primers designed for single nucleotide mutations in the 808 domestication candidate genes.

809 Table S5. Summary of double and triple mutants generated using the approach 810 described in Fig S4.

811 Table S6. Primers used for Sanger sequencing.

812 Table S7. Primers used for expression analysis of the Ta-elf6-1 early flowering 813 mutant.

814 Data S1. Genomic DNA Sequences of the candidate genes for pennycress 815 domestication obtained from Thlaspi (pennycress) version 1.0 gene annotations 816 and information on the mutation sites. 
817 Data S2. Predicted protein sequences of the candidate genes for pennycress

818 domestication obtained from Thlaspi version 1.0 gene annotations and mutation

819 and information on the mutation sites.

820 Data S3. Protein sequence alignments of Thlaspi arvense (pennycress) wild-type

821 sequences with the corresponding mutant and orthologous Arabidopsis

822 sequences.

823

824

825

826

827

828

829

830

831

832

833

834 


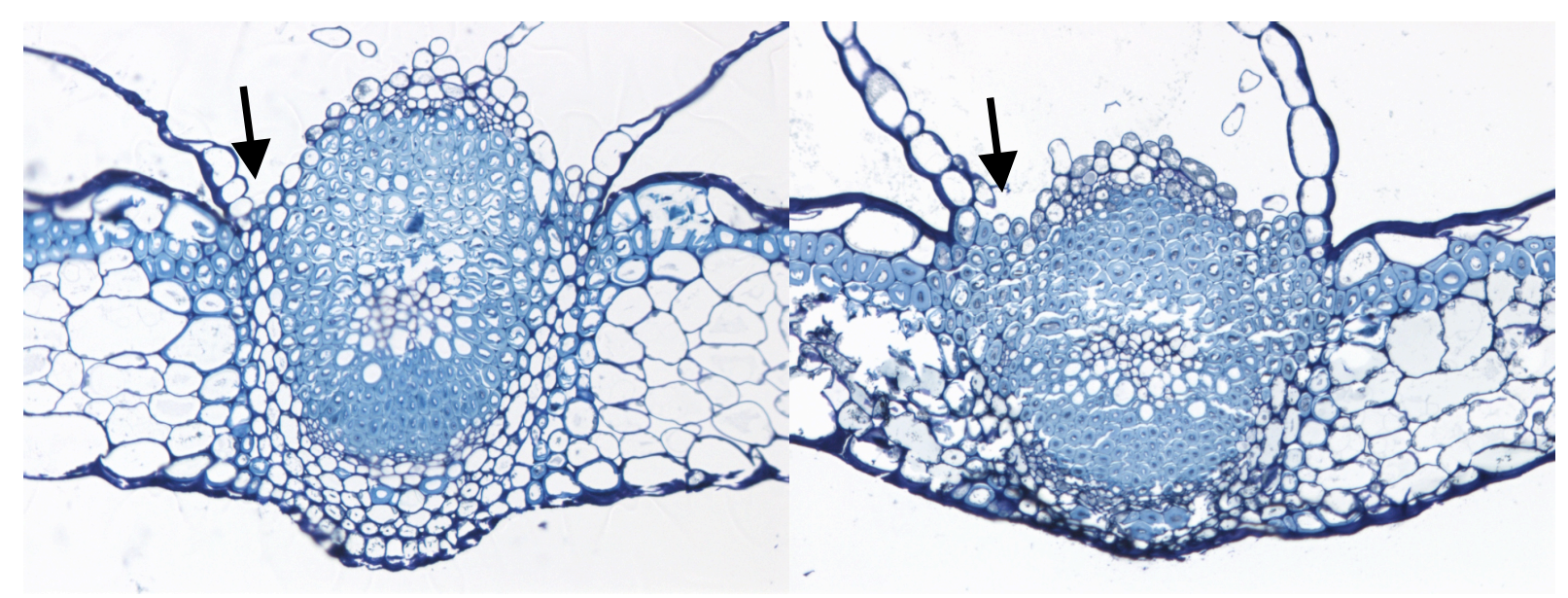

851 Figure S1. Comparisons of the separation layer of wild-type Spring 32 (left) and

852 ind-3 (right) seedpod sections stained with toluidine blue. Note the lack of a clear 853 separation layer in ind-3 (arrows). 


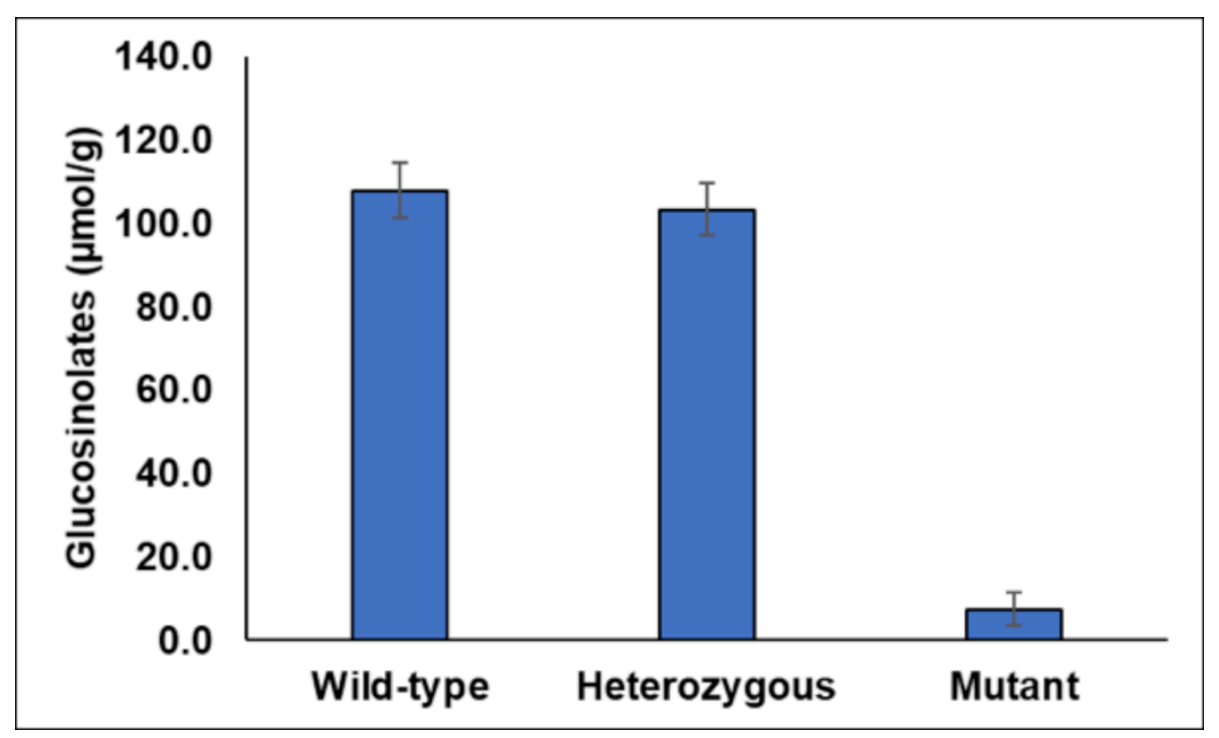

860 Figure S2: Average glucosinolate content of the progenies from the segregating

861 population of Ta-aop2-1 plants. Allele-specific markers were used to assess the aop2-1

862 genotype of members in the population and glucosinolate content was analyzed using

863 NIRS and confirmed with wet-lab assay. 
864

865

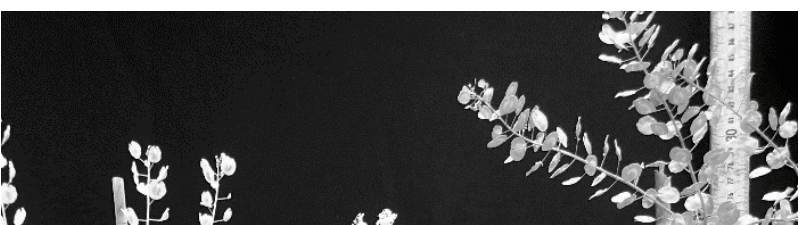

868 Figure S3. Comparisons of a wild-type pennycress plant with the "Nutty" aop2-1

869 and "canola-like-oil" fae1-1 rod1-1 mutants grown in controlled chambers. No

870 developmental defects were observed to be associated with the respective traits. 


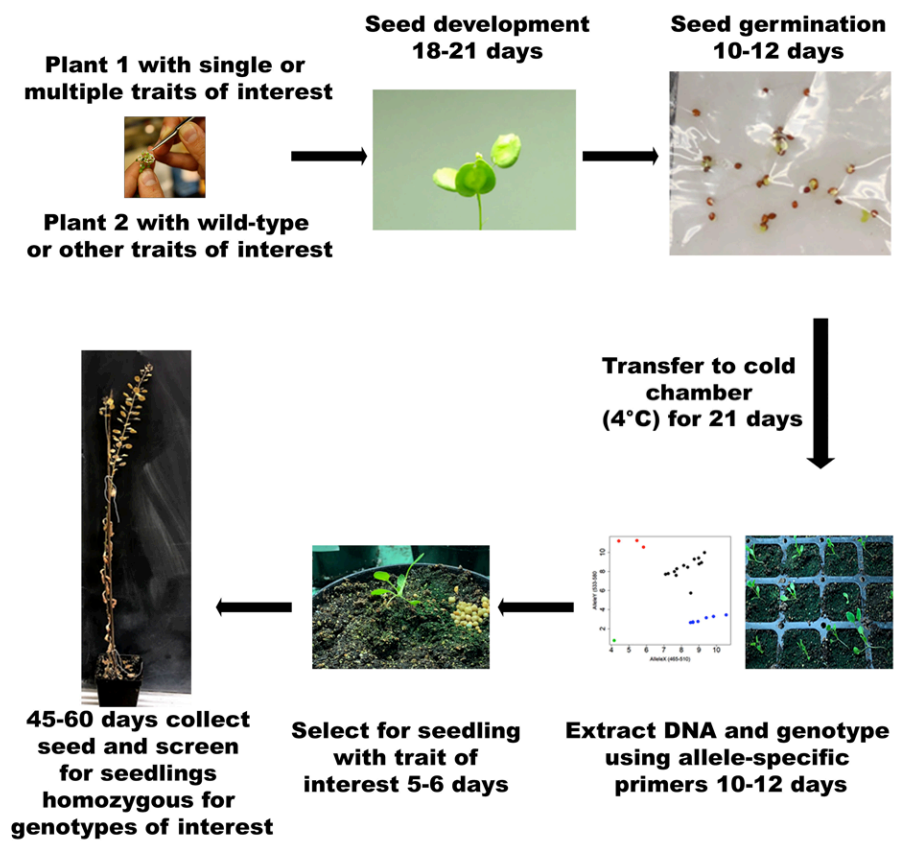

872

873 Figure S4. A schematic representation of pennycress life-cycle from seeds to a

874 mature plant. Seeds can be developed from the crossing event in 12-15 days.

875 Seeds can be propagated from seeds to mature in 75-80 days. This scheme of

876 propagating pennycress from would allow for minimum of three generations per

877 year.

878

879 
bioRxiv preprint doi: https://doi.org/10.1101/609990; this version posted April 16, 2019. The copyright holder for this preprint (which was not certified by peer review) is the author/funder, who has granted bioRxiv a license to display the preprint in perpetuity. It is made available under aCC-BY-NC-ND 4.0 International license.

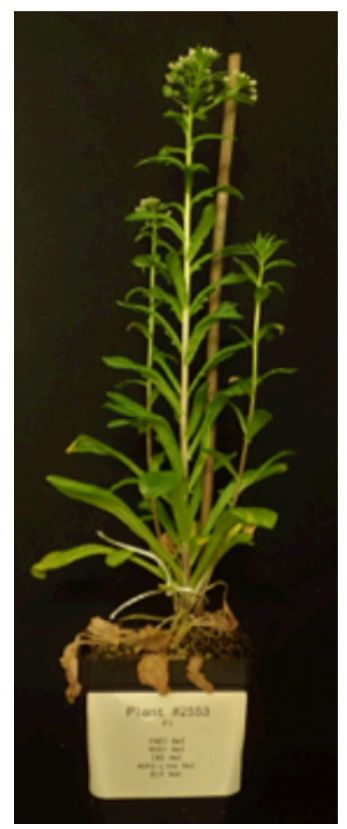

881 Figure S5. $F_{1}$ plant carrying all of the described mutations in this report and was 882 selected using the allele-specific primers and strategy described in Fig S4.

883 
bioRxiv preprint doi: https://doi.org/10.1101/609990; this version posted April 16, 2019. The copyright holder for this preprint (which was not certified by peer review) is the author/funder, who has granted bioRxiv a license to display the preprint in perpetuity. It is made available under aCC-BY-NC-ND 4.0 International license.

884

885 Table S1: Plant height and seed yield comparisons between wild-type and early

886 flowering mutant (elf6-1) grown in $1 \times 1 \mathrm{~m}$ plots in the field. No statistically

887 significant differences were observed among these lines ( $\pm \mathrm{sd}$ ).

888

889

\begin{tabular}{|l|l|l|}
\hline Line & Plant height $\mathbf{( c m )}$ & Seed yield $(\mathbf{g})$ \\
\hline Wild-type & $65( \pm 0.25)$ & $46.56( \pm 11.48)$ \\
\hline elf6-1 & $67.58( \pm 0.76)$ & $57.61( \pm 14.15)$ \\
\hline
\end{tabular}

890 
bioRxiv preprint doi: https://doi org/101101/609990; this version posted April 16, 2019. The copyright holder for this preprint (which was not certified by peer review) is the author/funder, who has granted bioRxiv a license to display the preprint in perpetuity. It is made available under aCC-BY-NC-ND 4.0 International license.

891 Table S2. Protein domain analysis to highlight the conserved region in the 892 Indehiscent gene (IND) using several databases.

893

894

\begin{tabular}{|c|c|c|c|c|c|}
\hline Gene & Database & Family number & Start Pos. & End Pos. & Gene Family \\
\hline Ta1.0_25465 & SMART & SM00353 & 98 & 147 & Myc-type, basic helix-loop-helix (bHLH) domain \\
\hline Ta1.0_25465 & Gene3D & G3DSA:4.10.280.10 & 84 & 154 & Helix-loop-helix DNA-binding domain superfamily \\
\hline Ta1.0_25465 & ProSiteProfiles & PS50888 & 92 & 141 & Myc-type, basic helix-loop-helix (bHLH) domain \\
\hline Ta1.0_25465 & SUPERFAMILY & SSF47459 & 97 & 151 & Helix-loop-helix DNA-binding domain superfamily \\
\hline Ta1.0_25465 & CDD & cd00083 & 96 & 146 & Myc-type, basic helix-loop-helix (bHLH) domain \\
\hline Ta1.0_25465 & Pfam & PF00010 & 100 & 141 & Myc-type, basic helix-loop-helix (bHLH) domain \\
\hline
\end{tabular}

895 
bioRxiv preprint doi: https://doi.org/10.1101/609990; this version posted April 16, 2019. The copyright holder for this preprint (which was not certified by peer review) is the author/funder, who has granted bioRxiv a license to display the preprint in perpetuity. It is made available under aCC-BY-NC-ND 4.0 International license.

896 Table S3. Summary of the mutations in the domestication related genes

897 characterized in this study.

898

899

900

\begin{tabular}{|c|c|c|c|}
\hline Scaffold Number & Gene & \# of Alleles & Mutation \\
\hline Ta_scaffold_10 & $\begin{array}{l}\text { ELF6 } \\
\text { Early Flowering6 }\end{array}$ & 1 & $\begin{array}{c}\text { Mutant: A7 } 25 \\
\text { Genomic pos: } 107096 \\
\text { cDNA pos: C952T } \\
\text { AA pos: His318Tyr }\end{array}$ \\
\hline Ta_scaffold_1003 & $\begin{array}{l}\text { IND } \\
\text { Indehiscent }\end{array}$ & 3 & $\begin{array}{l}\text { Mutants: E5 552; E5 550; Spring } 32 \text { NS } \\
\text { Genomic pos: } 6741,6754,6795 \\
\text { cDNA pos: C247T; G260A; G301A } \\
\text { AA pos: Pro83Ser; Arg87His; Ala101Thr }\end{array}$ \\
\hline Ta_scaffold_74 & $\begin{array}{c}A O P 2 \\
\text { Alkenyl- and Hydroxyalkyl-Producing2 }\end{array}$ & 1 & $\begin{array}{c}\text { Mutant: E3196 } \\
\text { Genomic pos: } 395125 \\
\text { cDNA pos: G289A } \\
\text { AA pos: Gly97Arg }\end{array}$ \\
\hline Ta_scaffold_45 & $\begin{array}{l}\text { FAE1 } \\
\text { Fatty Acid Elongation1 }\end{array}$ & 2 & $\begin{array}{l}\text { Mutants: V296; K1822 } \\
\text { Genomic pos: } 254962 ; \\
\text { cDNA pos: C1018T; G1349A } \\
\text { AA pos: GIn340Stop; Trp450Stop }\end{array}$ \\
\hline Ta_scaffold_199 & $\begin{array}{c}\text { ROD1 } \\
\text { Reduced Oleate Desaturation1 }\end{array}$ & 2 & $\begin{array}{l}\text { Mutants: d0422; E5 } 370 \text { P6 } \\
\text { Genomic pos: } 186474 ; 186409 \\
\text { cDNA pos: G678A; G743A } \\
\text { AA pos: Met226lle; Arg248Lys }\end{array}$ \\
\hline
\end{tabular}


901 Table S4. Allele-specific primers designed for single nucleotide mutations in the 902 domestication candidate genes.

903

904

\begin{tabular}{|c|c|c|}
\hline Trait & Primer Name & Sequence \\
\hline \multirow[t]{3}{*}{ Early Flowering } & elf6-1_C & ATCCCTGGTGTGACATCTCC \\
\hline & elf6-1_X & AAGCTCATGGTCCTCAACGTG \\
\hline & elf6-1_Y & AAGCTCATGGTCCTCAACGTA \\
\hline \multirow[t]{9}{*}{ Reduced Shatter } & ind-1_C & TCGTCGCTTACCCTTACGTT \\
\hline & ind-1_X & CGATCCAGCCACCGTTC \\
\hline & ind-1_Y & CGATCCAGCCACCGTTT \\
\hline & ind-2_C & TCTGAGTGTCGTCGCTTACC \\
\hline & ind-2_X & CCGTTCCTAAACCGAACCG \\
\hline & ind-2_Y & CCGTTCCTAAACCGAACCA \\
\hline & ind-3_C & CTGGCACCATCCTCTTCAAT \\
\hline & ind-3_X & GACACTCAGACGGTGGTGG \\
\hline & ind-3_Y & GACACTCAGACGGTGGTGA \\
\hline \multirow{3}{*}{$\begin{array}{c}\text { Reduced } \\
\text { Glucosinolates }\end{array}$} & aop2_C & CGTCACAATGATCAGGACGTA \\
\hline & aop2_X & CGGTCTTTCCGAGAGTATGG \\
\hline & aop2_Y & AACGGTCTTTCCGAGAGTATGA \\
\hline \multirow[t]{6}{*}{ Reduced Erucic Acid } & fae1-1_C & TAAAACCGGGGTGTGTTTGT \\
\hline & fae1-1_X & ACCCAATGTTGTTATGTTTTTCTG \\
\hline & fae1-1_Y & GACCCAATGTTGTTATGTTTTTCTA \\
\hline & fae1-2_C & AAACCCTGACCCTAAAGCAA \\
\hline & fae1-2_X & ATGAAGAGAGGGAACAAAGTGTG \\
\hline & fae1-2_Y & GATGAAGAGAGGGAACAAAGTGTA \\
\hline \multirow{6}{*}{$\begin{array}{c}\text { Reduced } \\
\text { polyunsaturated } \\
\text { fatty acids }\end{array}$} & rod1-1_C & GGTTCGATGATCGCATCTTT \\
\hline & rod1-1_X & CTCATCCTCTGCATTCTCCTC \\
\hline & rod1-1_Y & TCTCATCCTCTGCATTCTCCTT \\
\hline & rod1-2_C & GCGATGCTTTTTGACATCCT \\
\hline & rod1-2_X & CTCGTCCCGAGCAGCC \\
\hline & rod1-3_Y & CTCGTCCCGAGCAGCT \\
\hline
\end{tabular}

905

906 
bioRxiv preprint doi: https://doi.org/10.1101/609990; this version posted April 16, 2019. The copyright holder for this preprint (which was not certified by peer review) is the author/funder, who has granted bioRxiv a license to display the preprint in perpetuity. It is made available under aCC-BY-NC-ND 4.0 International license.

907 Table S5: Summary of double and triple mutants generated using the approach 908 described in Fig S4.

909

\section{Combination of alleles}

fae1-1/rod1-1

fae1-1/elf6-1

fae1-1/aop2-like-1

fae1-1/ind $1-1$

rod1-1/aop2-like-1

elf6-1/ind1-1

aop2-like-1/ind1-1

fae1-1/rod1-1/aop2-like-1

fae1-1/rod1-1/ind1-1 
bioRxiv preprint doi: https//doi org/101101/609990: this version posted April 16,2019 . The copyright holder for this preprint (which was not certified by peer review) is the author/funder, who has granted bioRxiv a license to display the preprint in perpetuity. It is made available under aCC-BY-NC-ND 4.0 International license.

912 Table S6. Primers used for Sanger sequencing.

913

914

\begin{tabular}{|c|c|c|c|}
\hline Trait & Gene & Forward Primer & Reverse Primer \\
\hline Early Flowering & ELF6 & CGTCCAAGCAGAAGAACATGG & CCAGTTGATCAATGTTTCTGC \\
\hline Reduced Shatter & IND1 & TGAAGGAGATGCAGTACACG & TATAACGGATGGCTTCGTCG \\
\hline Reduced Glucosinolates & AOP2 & TCGGAGGAGCTTAAGAAGTC & ACCTGATGCTCTTGTTACCG \\
\hline Reduced Erucic Acid & FAE1-1 & GACCTAAGTTCTTCTGTAGC & TAAAACCGGGGTGTGTTTGT \\
\hline Reduced Erucic Acid & FAE1-2 & GAGAAAACATCGTAGCCATC & AAACCCTGACCCTAAAGCAA \\
\hline Reduced PUFAs & ROD1 & CATGTGGGGTTTGGGTTAAC & GTTCAAGTAATTAACAGTATATTC \\
\hline
\end{tabular}

915 
bioRxiv preprint doi: https://doi.org/101101/609990; this version posted April 16, 2019. The copyright holder for this preprint (which was not certified by peer review) is the author/funder, who has granted bioRxiv a license to display the preprint in perpetuity. It is made available under aCC-BY-NC-ND 4.0 International license.

916 Table S7. Primers used for expression analysis of the Ta-elf6-1 early flowering 917 mutant.

918

919

\begin{tabular}{|c|c|c|}
\hline Gene & Forward Primers & Reverse Primers \\
\hline ELF6-qPCR & CCTGGTGAATTTGTTGTGA & GGACAGCATGGGAAGATA \\
\hline FLC-qPCR & GCTATCAACAAGCTTC & GCACCATGAGCTACTA \\
\hline Actin-qPCR & GTGAGACACACCATCACCAGAAT & TGTCGCCATCCAAGCTGTTCT \\
\hline Ubiquitin-qPCR & AGTTAAGAGGACTGTCTGG & TCCTGAACCATATCCTCT \\
\hline
\end{tabular}

920 
bioRxiv preprint doi: https://doi.org/10.1101/609990; this version posted April 16, 2019. The copyright holder for this preprint (which was not certified by peer review) is the author/funder, who has granted bioRxiv a license to display the preprint in perpetuity. It is made available under aCC-BY-NC-ND 4.0 International license.

Data S1. Genomic DNA Sequences of the candidate genes for pennycress domestication obtained from Thlaspi (pennycress) version 1.0 gene annotations and information on the mutation sites. (Exons - bold; Introns - small letters).

\section{Ta ELF6 \\ Ta-elf6-1 (highlighted red; substitution: C to T; cDNA pos:952)}

ATGGGTGATGTTGAAATTCCCAATTGGCTAAAAGCCTTGCCTTTGGCACCTGTCTTTAGACCTACGGACACCGAATTCG CAGATCCTATCGCGTATATATCGAAAATCGAGAAAGAGGCCAGTGCTTTTGGGATCTGCAAGATCATTCCTCCTTTACC CAAGCCGTCGAAAAAGTATGTTTTCTACAACTTGAACAAGTCTCTTTTGAGGTGTCCTGAATTGGCTTCGGATGTAGAC ATTTCGAAAGTGTGTCAAGAGGATAGAGCTGTGTTCACCACTAGGCAGCAAGAGTTAGGGCAGGCTGTAAAACGAAAGA AAGGAGGAGAGAGCAGTAAGAGCAATTCTCAAAGGAGTGGCGTTAAGCAGGTGTGGCAAAGTGGAGGCGTGTACACGTT GGAGCAGTTCGAATCTAAGTCAAAAACTTTCTACAAAAGCCAGTTAGGAACCACAAAAGAAGTGCCACCGGTTGTGGTT GAGGCATTGTTCTGGAAAGCAGCTTTAGAGAAGCCTATATACATAGAGTATGCAAATGATGTGCCTGGCTCGGCTTTCG GTGAACCAGAGGGTCATTTCAGGCATTTTCGGCAGAGAAAGAGGAGAGGGAGAGGATTTTATCAGAGGAAGGCAGAGGT CAGTGAAGACAGCGGAGTAGAAAACGGGACGAATAGTCAAGAACCAACCTGCAAGAATGGTGAGAAAACATTGCCTGAG GTAGCAAAGGCATCTCTTGCTTCTCCGAGTTTATTATCTCAGGATCCGTCCAAGCAGAAGAACATGGATATTGTTGATG AAATGGAAGGTACTGCAGGCTGGAAGCTCTCCAACAGTTCATGGAACCTTCAGATGATTGCACGTTCACCTGGATCTGT TACACGCTTCATGCCAGATGACATCCCTGGTGTCACATCTCCCATGGTTTATATCGGTATGTTGTTCAGCTGGTTTGCC TGGCACGTTGAGGACCATGAGCTTCACAGTATGAATTACCTTCACACTGGCTCGCCAAAGACGTGGTACGCTGTCCCTG GTGATTATGCATTTGACTTTGAAGAGGTTATCCGCAAAAATTCGTATGGCAGAAACATTGATCAACTGGgtacgttct tctgaaaagtactgctaaatatgatatactgtttctgtttatatagaaatgtttcgttggtgtaatacatcatacatgt gagaatgagatttcctagaatgattaccgcatccatatttttctttactagcacctttttttttgctttgtaagtga aatgtggctgacattgactatgatatgacgagagtttgtactcttgggaaattgcgttaggacttattgctttaaggtt attatgatagatatgagacgttgcaacacttcttatgaaatgcattgtccttctgtttctcattgactcttagctgttc tt tg tcact tcagCTGCTCTCACCCAACTAGGCGAAAAGACAACTCTTGTATCACCTGAGATGATAATTGCATCTGAC ATTCCCTGCTGTAGgtaggccttttaattttatttgaactttcacttctgttatgtggagatgtgaggcagtttgtgtt ttcttataactacgccaagctctgctatatctattttgtttcccacgtagGTTGGTACAGAATCCTGGTGAATTTGT TGTGACTTTTCCGAGGTCTTATCATGTAGGATTCAGCCACGgtaaaatgctttttt tct $t$ caacattcttaagtct tgtgactttactttggtcgtcccattttgcactcttcaaagtgtgtgagaaaatgtgaaaattcaaattcaaattga gtaaagctttggagaaaatgagtgttttacgacagagcataaggtgaggattgatcttctaattaggagaatgaagaa ccaaatttctattaagtagtagttatataagttgcatagtaaaagcggatagtttggcttcgattaggaatacaaattg caatattttttcagaatccttaactaagcagaattaatttaacgttttaaagGTTTTAACTGTGGGGAAGCCGCTAAT TTTGGAACTCCACAATGGCTCAACGTAGCTAAGGAAGCTGCTGTGCGACGGGCAGCCATGAATTATCTTCCCATGCTGT CCCATCAGCAGCTGCTATATCTCTTGACCATGTCCTTTGTTTCAAGGCAAATTTCCATGGCCTCTTTg tacataga cttttctgctggaacctgttaatcctcatattcttgtaatattaaattttcagAGTGCCACGATCATTACTACCAGG TGGTCGTAGCTCCCGACTGAGAGATCGTCAGAGAGAAGAAAGGGAGTTCCTTGTGAAAAAAGCTTTTGTAGAAGATATA CTGAACGAAAACAAGAATTTATCTGTTCTTCATCGAGAACCGGGATTTCGTTTGGTGATGTGGGACCCTGATTTACTCC CGCGTCATAGTGTACATGGTCTTGTAACTGTTGGGGGTGCTGCTGTTTCATCTCCAGCAGAGGGAAAAAATGAACTTGA GGAGAAGAATAAAGAGAAGACTACTCTTTTAGAGGAATTGAGTTTGTTCATGGAGAAGCTGAAAGATGTATACTACGAC GATGATGATGGTCTGCTTAATGATTTCCAGGTTGATTCTGGAACCTTGGCATGTGTGGCGTGTGGCGTTCTTGGCTTCC ССTTTATGTCTGTGGTACAGCCTTCTGAAAATGCATTAAATGATCTTTCAGAGAGACGAGGAGAGATAGgtaacagacC ctcattttttaaccaaactatgaactacaccatcttcgtttgaagcctgttaattgtgcttctatctattctacagAT GGTCAGGAAATTACGGCACTGTTGTCAGAAAAGTCTGACTGTGAATGGAACATGTCCTCCAGGTATATAAGACCTCGCA TTTTCTGCCTCGAACACACTATTGAGCTCCAGAGACTGCTGGAGTCACGAGGTGGACTGAAGTTCCTTGTAATTTGCCA TAAAGgtaagtacgcgtcatttgctattaaattcgatgccaaagagaatattttgatcattctgcttttaacttttttt ggaattgttgcagACTTTCAAAAATTTAAGGCATATGCGGCTATAGTGGCAGAGGAAGTTAAAGTCCCTTTCAGCTATG ATGATATCCTGTTAGAGAGTGCATCTAAAGAAGAGTTGAGTCTGATTGATCTTGCAATTGAAGATGAAGAAAACAACGA ACATGGCGTAGACTGGACCTCAAAACTTGGTATCAATTTACGGTACTGTGTTAAAGTGAGGAAAAATTCCCCTTCTACG AAAATTCAGCATGCACTGTCGCTAGGTGGCTTGTTCTCCGATACAAACCACATGCTAGATATGTCAACTATCAAATGGC TGCAGAGAAAATCACGCTCAAAAGCCAAACCCAGTTGTACCTCAAGCTTCACACCTCGTGAACATCTTGAAGTAAAAGT AGACAGAAAATTAGGGGAGAAGGAAAAAGTTGAATCCCAAGCCGGAAGAAAGGAAGAAAAGATCATCCAGTACTCGAGA AAGAAAAAGTTGAAGCCCAAGCCTTCTGAAGAACGAAGTCAGGAACTAACTATCTCAGCTAAATCAGAAGATTTTGAAA ACACATGCAACACACTTGCCAAAAGGTCACATCATCATGGGGCAATGCATTCTGATATGAACAATGAAATTGGAGATTT TGGGAGGAATGGGGTATCCTTTTCAGAAAATCATTGTAGCTCACCTTTCACTGGGGCACGCGGACAAGAACATCCCAAG ATCATTATCAAGTTTGGCTCAGCATTACATGGGAATATTACAAGCAGTTCTAGTTTGGTGAATGGAATCTCTGCTGACC TAACTTCCGTAACCAGAGAGCACCAAGGACACTCTATGACCAGCAATAATAATGGGTCGAACTCAAGTAATCATGATGG CCCAATAAAGCTGTCTGGTGAGCATGTCAGTGACGTGTCTGTACGTGATGTTGATGAAGCGGTTGAAATGAGCGACCAA 
bioRxiv preprint doi: https://doi.org/10.1101/609990; this version posted April 16, 2019. The copyright holder for this preprint (which was not certified by peer review) is the author/funder, who has granted bioRxiv a license to display the preprint in perpetuity. It is made available under aCC-BY-NC-ND 4.0 International license.

981

982

983

984

985

986

987

988

989

990

991

992

993

994

995

996

997

998

999

1000

1001

1002

1003

1004

1005

1006

1007

1008

1009

1010

1011

1012

1013

1014

1015

1016

1017

1018

1019

1020

1021

1022

1023

1024

1025

1026

1027

1028

1029

1030

1031

1032

1033

1034

1035

1036

1037

1038

1039

GAGTTCGAAGAACTGAGGTCTACCGTCACTAACATTGAGGAGGAACAGCAATCAGAGATGGTGAGACCAACCGCACTTC AGGTGGAGGGAGAGGAATCTATGTGTACGAGAGAAATCTTGAGCTCTGAAGATATTATGCACACTGAGCAGCAGCAAGA GCAAACTCAACTGGGTTTAGAAGTTCCTGAAACTGACATTGCCAGTGAGAACATAGTTGTGGACATGATCCATGATGAT GAACCTCTGGCAACTAGGGATATATTAAGTTCAAGCAACGGTGATCAAGCTTCTTCAAATGGCTTGCAAGCTCTAGATA ATGAACTTAGCATGGAGAGCGAAGTTGCAAGCTCAGAAAACACCGAGGTTATAGAGGCGTCGCCCAATTCTATTATGCG AGAAGCAAATAAGAAGCGGAGAATAGAATCAGAGTCTGAGACAAATGATAATCCAGATGGTAGCATTGGTTTCATAAGG AGTCCTTGTGAAGGGTTGAGGTCAAGGGGTAGGAGGAGAGTGACGCGTGAAGCTTCAGTCAGTCTCACTGAAACGAGCG ATGAAGAGAAGAAACCCGCTGCGAAAAGGTTCAAGAAAACTCCAAAGACTCGCTCGGGGAGTCATCACCAAGAAGACTC CACGACAAGTCACCACAACCGTTGTAACCTAGAGGGATGCAAGATGACTTTCAAGAGTAAAGCAGAGTTACAAGCTCAC CAAAGAAACCGCTGCGCACATGAAGGGTGTGGAAAAAAATTCAGGGCTCACAAATATCTGGTGCTTCATCAACGTGTTC ATAACGATGATAGACCTTTTGTGTGCTCTTGGAAAGGATGTTCCATGACTTTCAAATGGCCATGGGCGAGGACCGAGCA TTTGCGTCTGCACACGGGAGAGCGACCATACAAATGCAAGGTCGATGGATGTGGAATGTCGTTTAGGTTTGTGTCGGAT TACAGCCGCCATAGACGGAAAAAGGGGCATTATGTGACATAG

\section{Ta IND}

Ta-ind-1 (highlighted red; substitution: C to T; cDNA pos:247) Ta-ind-2 (highlighted red; substitution: $G$ to A; cDNA pos:260) Ta-ind-3 (highlighted red; substitution: $G$ to $A$; cDNA pos:301)

ATGAATTGGAACAAACCTAATGATCTCATCACACAAGAATACCCCTTTCTCCACGATCCTCATCTCATGATAGATCCAC CTCCCGAAACCCTAAGTCATTTCCAGCCCCCGCCGACACTTTTCTCCGGTCACGGAGGGGAGGAAGAAGAAGAAGAAGA TAATGAAGAGGAAGAGATGGATGCGATGAAGGAGATGCAGTACACGATCGCTGCCATGCAGCCCGTGGACATCGATCCA GCCACCGTTCCTAAACCGAACCGCCGTAACGTAAGGGTAAGCGACGACACTCAGACGGTGGTGACTCGTCGGCGTCGAG AAAAGATAAGCGAGAAGATCCGAATATTGAAGAGGATGGTGCCAGGCGGTGCGAAGATGGACACAGCCTCCATGCTCGA CGAAGCCATCCGTTATACCAAGTTCTTGAAACGGCAGGTGAAGCTTCTTCAGCCTCACTCTCAGCTTGGAGCTCCTATG TCTGACCCСTCTTGCCTTTGTTATTACCACAACTCCCAAACCTAA

\section{Ta AOP2}

Ta-aop2-1 (highlighted red; substitution: G to A; cDNA pos:289)

ATGGGTTCACTTTCAAACACTCCTCAGCTTCCAGTCATCTACСTCTCGGACCAAACCCTAAAACCAGGAAGCTCAAAGT GGGTTGAAGTCAGGAGTGATGTCCGTAAAGCTCTTGAAGAGTACGGCGGTTTCGAGGTGTCGTACGATAGAGTGTCGGA GGAGCTTAAGAAGTCGGTTTTGCAAGCCATGGAAGAGCTTTTCGCGTTACCAGTTGAGGCTAAACAGAGAAACGTCTCT ССTAAACCСTTCAGCGGTTATTCCACTCATAACGGTCTTTCCGAGAGTATGGGGATCCAGGATCCTCATGTTTTGGACA AAGTTTACGAGTTTACTCAACTTCTACGTCCTGATCATTGTGACGGTAACAAGAGCATCAGgtaattg tgaaa a $a$ a tcaatattgcttcataatataaaatactcaatattgcttcctaatctttttggcagtttatttcactacataaataa acccgcttttacatttttattgtttgtggtataagaatattagttcactcaaacagcatgaaactaataattgaaattt tgtatttgtgtgaaaactttagttcacttaataacatttttgttgtttgtgttgtaaacagCGAAACGATCCAGACG TTTTCAGAGAAgttatcagaattggatataatggtgagaagaatggtaatggaaagcttcgggatagagaagtaccttg acaaacacctgaactcaacgaattaccgtctgcggctgatgaagtatatagcaccgcctgatgctgatgctactaatgt tgcggctgatgccaaagatgctgatgataatgctaagacgattacaaatgataaagttgatgcggctggtgctaatgat gtagatgctggtgatatcgctaatggtattgctaatcttcatattggtgatgatgctaacgctggtgctaatggtgctg gtgttgatgctaatgatggtggtgaggatgctaagactggtgaggatgctaagactggtgaatgtgctagtgttaagtc talgccgaagatggtactgatgttaltgccagTGCTGATGCTGGTGTTACTGTTGGCTCTAATGCTGATGCTAATGCT AATGCTAATGCTAATACTAGTACTGATGCTGGTGTTGGCGATAGTGTTAAAGCTAATGGTGGTGCTGATGATGTTGAGA AGAAATTGGGTCTACCTTCTCACACTGATAAGAACCTTATAACGGTGCTTTATCAATACGAGATTGAAGGCTTGGAGGT TCTAACCAAAGATGACAAGTGGATCAGACTCAAACCATCTCATAATTCTTTCGTTGTTATGGCTGGAGATTCTCTATAC gtaagtttccaacttcttcttcttcttcttttctttttttaagttgacactcacacgtactgacgtacacgttggtgg atttaaagtaaccctagtggagaagaagatgaattttcatttacattatatcataaacctactttttaaltagaata agaataattaaactaaacccattttttattggctcactatggcctaagaatataattaaatattatataggctcaa taagtcataatattctttagcctatagaatatttttaagtattcaataattaaaattattttatagcatatagaatat tttatgggctcaataattacaagtattctacaggatcaccatggcctaagaataatcaaagtaaaccgaattttaaa attacaggtatagagaaagaaaaagaaagctaaattaaaaccaagaataagttaaaatgtatgagaagtaacaaac ttagtggcgaaaagagaaaagattattattcagtcacgttcacgctcactatggaccaacttatcctatagaaacta ttaatatttcttgattttattcgctcttatcactttcacaagtgcatgtttgactaaagcgttataacatgatgttt tgttttcttctgatcatgatctcttgctgttacttacaaacaaacaaatggtgattttgtttttgtttttttttgcag GCACTTATGAATGGTAGACTAACTCGTCCCTTTCATCGAGTAAGAGTAACGGAGAAAAAGAAGACAAGATATTCAATAG 
bioRxiv preprint doi: https://doi.org/10.1101/609990; this version posted April 16, 2019. The copyright holder for this preprint (which was not certified by peer review) is the author/funder, who has granted bioRxiv a license to display the preprint in perpetuity. It is made available under aCC-BY-NC-ND 4.0 International license.

1040

1041

1042

1043

1044

1045

1046

1047

1048

1049

1050

1051

1052

1053

1054

1055

1056

1057

1058

1059

1060

1061

1062

1063

1064

1065

1066

1067

1068

1069

1070

1071

1072

1073

1074

1075

1076

1077

1078

1079

1080

1081

1082

1083

1084

1085

1086

1087

1088

1089

1090

1091

1092

1093

1094

1095

1096

1097

1098

1099

CATTGTTCTCGGCTCCAACCGCAGATTACATCATAGACACACCAAAAGAACTTGTGGACGAGAAGCATCCACGTATCTT CGAACCATTTAACTATAACGACTTGATGAGTTTCTATCATAGTGAAGCTGGTCGTAAAGCTCGATCTACTCTTGATGCT TTCTGTGCCGTCTCTCGAGCATAA

\section{Ta FAE1}

Ta-fae1-1 (highlighted red; substitution: $C$ to $T$; cDNA pos:1018)
Ta-fae1-2 (highlighted red; substitution: $G$ to A; cDNA pos:1349)

ATGACGTCCGTTAACGTTAAGCTCCTTTACCATTACGTCATCACCAACTTTTTCAACCTTTGCTTCTTCCCGTTAGCGG CGATCGTTGCCGGAAAAGCCTCTCGGCTTACCACAAACGATCTTCACCACTTCTACTATTCСTATCTCCAACACAACCT AATAACCATATCTCTACTCTTTGCCTTCACCGTTTTCGGTTTGGCTCTCTACATCGTAACCCGGCCCAAACCGGTTTAC CTCGTTGACCATTCCTGCTACCTTCCACCATCGCATCTTAGAAGCAGTATCTCTAAGGTCATGGATATCTTCTATCAAG TAAGATTAGCCGATCCTTTACGGAACGCGGCAAGCGATGATTCGTCCTGGCTTGATTTCTTGAGGAAGATTCAGGAGCG GTCTGGTCTAGGCGATGAAACCCACGGCCCCGAGGGACTGCTTCAGGTCCCTCCACGGAAGACTTTTGCCGCGGCGCGT GAAGAAACAGAGCAAGTGATCATCGGTGCGCTCGAAAAACTATTCGAGAACACCAAAGTTAACCCTAAAGAGATTGGTA TACTTGTGGTGAACTCAAGCATGTTTAATCCGACTCCTTCGCTCTCGGCGATGGTTGTTAATACTTTCAAGCTCCGAAG CAACATCAGAAGCTTTAATCTTGGAGGAATGGGTTGTAGTGCCGGCGTTATAGCCATTGATCTGGCTAAGGACTTGTTG CATGTCCATAAAAACACTTATGCTCTTGTGGTGAGCACAGAGAACATCACTTACAACATTTATGCTGGTGATAACAGAT CCATGATGGTTTCGAATTGCTTGTTCCGTGTTGGTGGGGCCGCGATTTTGCTCTCCAACAAGCCGAGGGACCGGAGACG GTCCAAGTACCAGCTACTTCACACGGTTCGGACGCATACCGGAGCTGACGACAAGTCTTTCCGATGTGTGCAACAAGAA GACGACGAGAGCGGTAAAACCGGGGTGTGTTTGTCCAAGGACATAACCGGTGTTGCCGGGAGAACTGTTCAGAAAAACA TAACAACATTGGGTCCGTTGGTTCTTCCTTTTAGCGAGAAATTTCTTTTTTTCGTTACCTTCATCGCCAAGAAACTCTT TAAAGACAAGATCAAACATTACTACGTCCCGGATTTCAAGCTTGCTATCGACCATTTTTGTATTCATGCCGGAGGCAGA GCCGTGATCGATGTGCTACAGAAGAACTTAGGTCTATTGCCGATCGATGTGGAGGCATCTAGGTCAACGTTACATAGAT TTGGGAACACTTCGTCTAGCTCAATTTGGTATGAATTGGCGTACATAGAGGCAAAAGGAAGGATGAAGAGAGGGAACAA AGTTTGGCAGATTGCTTTAGGGTCAGGGTTTAAGTGTAATAGTGCGGTTTGGGTGGCTCTACGCAATGTCAAGGCTTCG ACAAATAGTCCTTGGGAACATTGCATTGATAGATATCCAGATGCAATTGATTCTGATTCGGGTAAGTCAGAGACTCGTG TCCAAAACGGTCGGTCCTAA

\section{Ta ROD1}

Ta-rod1-1 (highlighted red; substitution: C to T; cDNA pos:678) Ta-rod1-2 (highlighted red; substitution: $C$ to $T$; cDNA pos:743)

ATGTCAACTAAAACCGTCGTCCCTCTCCGTCGCAGATCTAAGCCCCTTAACGGAAATCACACTAACGGCGTCGCCATTG ACGGAAGCCTCGACGACGACCACAACCGTCGCATCGGATCAGTAAATAGCCAAATGGATAACATTGCTAAGAAAACGGA CGACGGCTACGCAAACGGCGGAGGAGGAGGAGGAGGAGGGAAAAGCAAGGCGTCGTTTATGACGTGGACGGCGCGTGAC GTTGTGTACGTGGCGAGGTACCATTGGATACCGTGTTTGTTCGCGGTCGGGGTTCTGTTCTTCACGGGCGTGGAGTACA CGCTCCAGATGATTCCCGCGAGGTCTGAGCCGTTCGATATTGGGTTTGTGGCCACGCGCTCTCTGAATCGCGTCTTGGC AAATTCACCGGATCTTAACACCGTCTTAGCCGCTCTAAACACGg taatttcgtactaattaatttaggg taa aa a tat agtatttaataatgactatcctcaattcctttcatgcttcacctaatattttgttttttttcgttgtcattaaaatcgt aataatatattgagttagtcaaatgaaaaaacaagtggcggtagtgattggaaacaaatctcagatcttttatctgtt taataaggtatttaattatccagctggaattatgctgtcaagtgtcaacacagtagtagtaacatgcaatggaatttct caatagaaaaggtcttaattagtatagataattagtggacaaaatgtagttaatgtaatctctttgctaagtagtta tcataatcatctttttaacaactgccattttgtctgtgtgtttgttttacaacgaagtagtagtagaatagatcgcttt ttagcttttgaaagtttcgaacccaaggaaaaggacacatgggttatgagttggagacacgatcacatgcaaacagag agattggttaaattatcgactttttgtagtactttttaaaaaaaactatttatataaaaacatggtggatggtgggg a cagGTGTTCGTAGGGATGCAAACGACGTATATTGTATGGACATGGTTAATGGAAGGACGACCACGAGCCACCATCTCG GCTTGCTTCATGTTTACTTGTCGAGGCATTCTTGGTTACTCTACTCAGCTCCСTCTTCCTCAGgttccaatcaacact ttcttctatctctttcttaattaaaataattaccaattaactaalgctaatcagtcgatatatcatagttccaacgt tttggacgtgtgatttccattggccactaccatataaacaacagagtctctttattcattattcaatatatatttgag tattgatattattcatagggaggtttcatttgtactatcaataaatttctacaactcttggatttttctgctacatt ttgtagttatttttttaattacttttaaaacttgtgaataggagagactaatagtagtacgtaatatgattgtatcaa atgctttaacatgtggggtttgggttaactatcatcatttcatagatcactattttgttttcgtttgttacctaacttt ttgttatctttgaaaataatgttccacgagttgattgactggacataaaatcagattctctcactcatttacgttct acggttctagccactcgttttttcttttctttctgtggtgtaacacgtagataatggattttctatgtgtgtcgtct tgctcaagaataataaatgtggttaaaggttaaatatagctctggaaattaattatctcctctttttttattaaccagG ATTTTCTAGGATCAGGTGTCGATTTTCCGGTGGGAAACGTCTCGTTCTTCCTCTTCTACTCGGGTCACGTCGCCGGTTC GATGATCGCATCTTTGGACATGAGGAGAATGCAGAGGATGAGACTAGCGATGCTTTTTGACATCCTCAATGTATTACAA 
bioRxiv preprint doi: https://doi.org/101101/609990; this version posted April 16, 2019. The copyright holder for this preprint (which was not certified by peer review) is the author/funder, who has granted bioRxiv a license to display the preprint in perpetuity. It is made available under aCC-BY-NC-ND 4.0 International license.

1100

TCGATCAGGCTGCTCGGGACGAGAGGACACTACACGATTGATCTCGCTGTCGGAGTTGGCGCTGGGATTCTCTTTGATT

1101 CATTCGCCGGCAAGTACGAAGAGATGATAAGCAAGAGACACAATTTAGTCAATGGTTTTGGTTTGATTTCGAAAGACTC

1102 GCTAGTCAATTAA

1103

1104 
bioRxiv preprint doi: https://doi.org/10.1101/609990; this version posted April 16, 2019. The copyright holder for this preprint (which was not certified by peer review) is the author/funder, who has granted bioRxiv a license to display the preprint in perpetuity. It is made available under aCC-BY-NC-ND 4.0 International license.

1105 Data S2. Predicted protein sequences of the candidate genes for pennycress 1106 domestication obtained from Thlaspi version 1.0 gene annotations and mutation 1107 and information on the mutation sites.

1108

1109

1110

1111

MGDVEI PNWLKALPLAPVFRPTDTEFADPIAY ISKIEKEASAFGICKI I PPLPKPSKKYVFYNLNKSLLRCPELASDVD ISKVCQEDRAVFTTRQQELGQAVKRKKGGESSKSNSQRSGVKQVWQSGGVYTLEQFESKSKTFYKSQLGTTKEVPPVVV EALFWKAALEKPIYIEYANDVPGSAFGEPEGHFRHFRQRKRRGRGFYQRKAEVSEDSGVENGTNSQEPTCKNGEKTLPE VAKAS LASP S LLSQDPSKQKNMDIVDEMEGTAGWKLSNSSWNLQMIARS PGSVTRFMPDD I PGVTS PMVY IGMLFSWFA WHVEDHELHSMNYLHTGS PKTWYAVPGDYAFDFEEVIRKNSYGRNIDQLAALTQLGEKTTLVSPEMIIASDIPCCRLVQ NPGEFVVTFPRSYHVGFSHGFNCGEAANFGTPQWLNVAKEAAVRRAAMNYLPMLSHQQLLYLLTMSFVSRQISMASLVP RSLLPGGRS SRLRDRQREEREFLVKKAFVEDI LNENKNLSVLHRE P GFRLVMWDPDLLPRHSVHGLVTVGGAAVSSPAE GKNELEEKNKEKTTLLEELSLFMEKLKDVYYDDDDGLLNDFQVDSGTLACVACGVLGFPFMSVVQP SENALNDLSERRG EI DGQE ITALLSEKSDCEWNMSSRY IRPRIFCLEHT IELQRLLESRGGLKFLVICHKDFQKFKAYAAIVAEEVKVPFSY DDILLESASKEELS LI DLAIEDEENNEHGVDWTSKLG INLRYCVKVRKNS PSTKIQHALSLGGLFSDTNHMLDMST I KW LQRKSRSKAKPSCTSSFTPREHLEVKVDRKLGEKEKVESQAGRKEEKI IQYSRKKKLKPKPSEERSQELTISAKSEDFE NTCNTLAKRS HHHGAMHS DMNNE I GDFGRNGVS F SENHCS S P FTGARGQEHPK I I I KFGSALHGN I TS S S SLVNGI SAD LTSVTREHQGHSMTSNNNGSNSSNHDGPIKLSGEHVSDVSVRDVDEAVEMSDQEFEELRSTVTNIEEEQQSEMVRPTAL QVEGEESMCTRE ILSSEDIMHTEQQQEQTQLGLEVPETDIASENIVVDMI HDDE PLATRD I LSSSNGDQASSNGLQALD NELSMESEVASSENTEVIEAS PNS IMREANKKRRIESESETNDNP DGS I GFIRS PCEGLRSRGRRRVTREASVS LTETS DEEKKPAAKRFKKTPKTRSGSHHQEDSTTSHHNRCNLEGCKMTFKSKAELQAHQRNRCAHEGCGKKFRAHKYLVLHQRV HNDDRP FVCSWKGCSMTFKWPWARTEHLRLHTGERPYKCKVDGCGMSFRFVSDYSRHRRKKGHYVT

MNWNKPNDLITQEYPFLHDPHLMI DP PPETLSHFQP P PTLFSGHGGEEEEEEDNEEEEMDAMKEMQYT IAAMQPVDIDP ATVPKPNRRNVRVSDDTQTVVARRRREKISEKIRILKRMVPGGAKMDTASMLDEAIRYTKFLKRQVKLLQPHSQLGAPM SDPSCLCYYHNSQT*

Conserved bHLH region is underlined.

\section{Ta AOP2-like}

Ta-aop2-1 (bold red; Substitution: Gly to Arg; AA pos:97)

MGSLSNTPQLPVIYLSDQTLKPGSSKWVEVRSDVRKALEEYGGFEVSYDRVSEELKKSVLQAMEELFALPVEAKQRNVS PKPFSGYSTHNGLSESMGIQDPHVLDKVYEFTQLLRPDHCDGNKS I SETIQTFSENADAGVTVGSNADANANANANTST DAGVGDSVKANGGADDVEKKLGLPSHTDKNLITVLYQYEIEGLEVLTKDDKWIRLKPS HNSFVVMAGDSLYALMNGRLT RPFHRVRVTEKKKTRYSIALFSAPTADYIIDTPKELVDEKHPRI FEPENYNDLMSFYHSEAGRKARSTLDAFCAVSRA

\section{Ta FAE1}

Ta-fae1-1 (bold red; Substitution: GIn to stop; AA pos:340) Ta-fae1-2 (bold red; Substitution: Trp to stop; AA pos:450)

\footnotetext{
MTSVNVKLLYHYVITNFFNLCFFPLAAIVAGKASRLTTNDLHHFYYSYLQHNLITISLLFAFTVFGLALYIVTRPKPVY LVDHSCYLPPSHLRSS I S KVMD I FYQVRLADP LRNAAS DDS SWLDF LRKIQERS GLGDETHGPEGLLQVP PRKTFAAAR EETEQVIIGALEKLFENTKVNPKEI GILVVNSSMFNPTPS LSAMVVNT EKLRSNIRS FNLGGMGCSAGVIAIDLAKDLL HVHKNTYALVVSTENITYNIYAGDNRSMMVSNCLFRVGGAA I LLSNKPRDRRRSKYQLLHTVRTHTGADDKSFRCVQQE DDESGKTGVCLSKDITGVAGRTVQKNITTLGPLVLPFSEKFLFFVTFIAKKLFKDKIKHYYVPDFKLAIDHFCIHAGGR AVIDVLQKNLGLLP IDVEASRSTLHRFGNTSSSS IWYELAY IEAKGRMKRGNKVWQ IALGSGFKCNSAVWVALRNVKAS TNSPWEHCIDRYPDAIDSDSGKSETRVQNGRS *
}

1161 
bioRxiv preprint doi: https://doi org/101101/609990; this version posted April 16, 2019. The copyright holder for this preprint (which was not certified by peer review) is the author/funder, who has granted bioRxiv a license to display the preprint in perpetuity. It is made available under aCC-BY-NC-ND 4.0 International license.

1162

1163 Ta ROD1

1164 Ta-rod1-1 (bold red; Substitution: Met to lle; AA pos:226)

1165 Ta-rod1-2 (bold red; Substitution: Arg to Lys; AA pos:248)

1166

1167

MSTKTVVPLRRRSKPLNGNHTNGVAI DGSLDDDHNRRIGSVNSQMDNIAKKTDDGYANGGGGGGGGKSKASFMTWTARD

1168

VVYVARYHWI PCLFAVGVLFFTGVEYTLQMIPARSEPFDIGFVATRSLNRVLANSP DLNTVLAALNTVFVGMQTTY IVW

1170

TWLMEGRPRATISACFMFTCRGILGYSTQLPLPQDFLGSGVDFPVGNVSFFLFYSGHVAGSMIAS LDMRRMQRMRLAML

1171

FDILNVLQS IRLLGTRGHYTIDLAVGVGAG I LFDSFAGKYEEMISKRHNLVNGFGL I SKDSLVN* 
bioRxiv preprint doi: https://doi org/10.1101/609990; this version posted April 16, 2019. The copyright holder for this preprint (which was not certified by peer review) is the author/funder, who has granted bioRxiv a license to display the preprint in perpetuity. It is made available under aCC-BY-NC-ND 4.0 International license.

1172 Data S3. Protein sequence alignments of Thlaspi arvense (pennycress) wild-type

1173 sequences with the corresponding mutant and orthologous Arabidopsis sequences. At the

1174 locations of the mutations, wild-type amino acids are highlighted in red and mutant

1175 amino acids in blue.

1176

1177

1178

1179

\title{
ELF6 - EARLY FLOWERING 6 (AT5G04240)
}

\begin{abstract}
At $-\mathrm{ELF} 6$
Ta-ELF 6

Ta-elf6-1

MGNVEIPNWLKALPLAPVFRPTDTEFADPIAYISKIEKEASAFGICKI IPPLPKPSKKYV MGDVE I PNWLKALPLAPVFRPTDTEFADPIAYISKIEKEASAFGICKIIPPLPKP SKKYV MGDVEIPNWLKALPLAPVFRPTDTEFADPIAYISKIEKEASAFGICKIIPPLPKPSKKYV

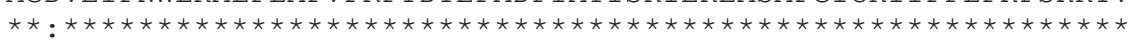

1181

1182

1183

118

At-ELF 6

Ta-ELF 6

Ta-elf6-1

1187

1188

At-ELF 6

Ta-ELF 6

Ta-elf6-1

1191

1192

1193

1194

At-ELF 6

Ta-ELF 6

Ta-elf6-1

1196

1197

1198

1199

At-ELF 6

Ta-ELF 6

Ta-elf6-1

At-ELF 6

Ta-ELF 6

Ta-elf6-1

FYNLNKSLLKCPELVSDVDISKVCKEDRAVFTTRQQELGQTVKKNK-GEKGKSNSQRSGV FYNLNKSLLRCPELASDVDISKVCQEDRAVFTTRQQELGQAVKRKKGGESSKSNSQRSGV FYNLNKSLLRCPELASDVDISKVCQEDRAVFTTRQQELGQAVKRKKGGESSKSNSQRSGV

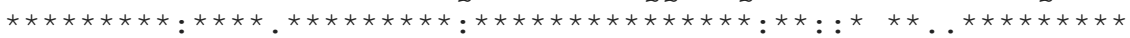

KQVWQSGGVYTLDQFEAKSKAFYKTQLGTVKELAPVVIEALFWKAALEKPIYIEYANDVP KQVWQSGGVYTLEQFESKSKTFYKSQLGTTKEVPPVVVEALFWKAALEKPIYIEYANDVP KQVWQSGGVYTLEQFESKSKTFYKSQLGTTKEVPPVVVEALFWKAALEKPIYIEYANDVP

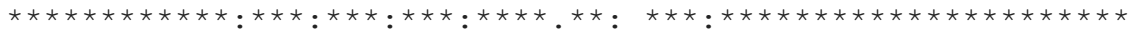

GSAFGEPEDHFRHFRQRKRRGRGFYQRKTENN-----------DPS GKNGEKS S PEVEK GSAFGEPEGHFRHFRQRKRRGRGFYQRKAEVSEDSGVENGTNSQEPTCKNGEKTLPEVAK GSAFGEPEGHFRHFRQRKRRGRGFYQRKAEVSEDSGVENGTNSQEPTCKNGEKTLPEVAK

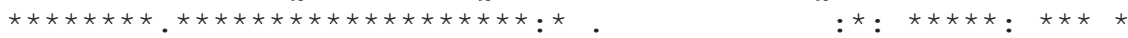

APLASTSLSSQDSSKQKNMDIVDEMEGTAGWKLSNSSWNLQMIARSPGSVTRFMPDDIPG ASLASPSLLSQDP SKQKNMDIVDEMEGTAGWKLSNSSWNLQMIARSPGSVTRFMPDDI PG ASLASPSLLSQDPSKQKNMDIVDEMEGTAGWKLSNSSWNLQMIARSPGSVTRFMPDDIPG

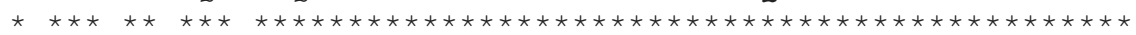

VTSPMVYIGMLFSWFAWHVEDHELHSMNYLHTGSPKTWYAVPCDYALDFEEVIRKNSYGR VTSPMVYIGMLFSWFAWHVEDHELHSMNYLHTGSPKTWYAVPGDYAFDFEEVIRKNSYGR VTSPMVYIGMLFSWFAWYVEDHELHSMNYLHTGSPKTWYAVPGDYAFDFEEVIRKNSYGR

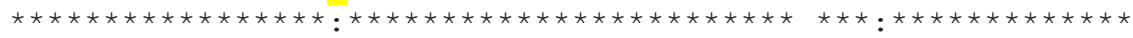

NIDQLAALTQLGEKTTLVSPEMIVASGIPCCRLVQNPGEFVVTFPRSYHVGFSHGFNCGE NIDQLAALTQLGEKTTLVSPEMI IASDIPCCRLVQNPGEFVVTFPRSYHVGFSHGFNCGE NIDQLAALTQLGEKTTLVSPEMI IASDIPCCRLVQNPGEFVVTFPRSYHVGFSHGFNCGE

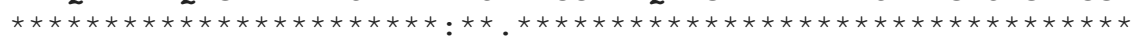

AANFGT PQWLNVAKEAAVRRAAMNY L PMLS HQQLLYLLTMS FVSR-------VPRSLLPG AANFGT PQWLNVAKEAAVRRAAMNY L PMLS HQQLLYLLTMS FVSRQ I SMAS LVPRSLLPG AANFGT PQWLNVAKEAAVRRAAMNYL PMLS HQQLLYLLTMS FVSRQ I SMAS LVPRSLLPG

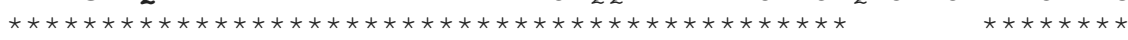

GRS SRLRDRQREEREFLVKRAFVEDI LNENKNLSVLLREPGSRLVMWDPDLLPRHSALAL GRSSRLRDRQREEREFLVKKAFVEDI LNENKNLSVLHRE PGFRLVMWDPDLLPRHSVHGL GRSSRLRDRQREEREFLVKKAFVEDI LNENKNLSVLHREPGFRLVMWDPDLLPRHSVHGL

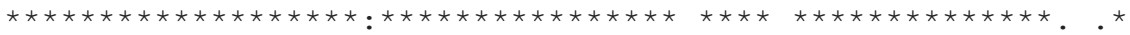

AAAGVAGASAVSPPAVAKKELEEGHSELQNKEKT S LLEELSLFMEKLNDVYYDDDDGLLN VTVG---GAAVSSPAEGKNELE-----EKNKEKTTLLEELSLFMEKLKDVYYDDDDGLLN VTVG---GAAVSSPAEGKNELE-----EKNKEKTTLLEELSLFMEKLKDVYYDDDDGLLN

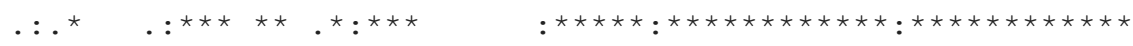

DFQVDTGTLPCVACGVLGFPFMSVVQPSEKALKDLSERQGETDAQE IMTLSSEKSDCEWK DFQVDSGTLACVACGVLGFPFMSVVQPSENALNDLSERRGEIDGQEITALLSEKSDCEWN DFQVDSGTLACVACGVLGFPFMSVVQPSENALNDLSERRGEIDGQEITALLSEKS DCEWN

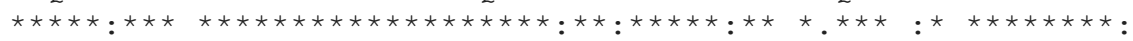


bioRxiv preprint doi: https://doi.org/10.1101/609990; this version posted April 16, 2019. The copyright holder for this preprint (which was not certified by peer review) is the author/funder, who has granted bioRxiv a license to display the preprint in perpetuity. It is made available under aCC-BY-NC-ND 4.0 International license.

\begin{abstract}
At-ELF 6
Ta-ELF 6

Ta-elf $6-1$

TSSRYIRPRIFCLEHTIELQRLLQSRGGLKFLVICHKDFQKFKAHAAIVAEEVKVPFSYD MSSRYIRPRIFCLEHTIELQRLLESRGGLKFLVICHKDFQKFKAYAAIVAEEVKVPFSYD MSSRYIRPRIFCLEHTIELQRLLESRGGLKFLVICHKDFQKFKAYAAIVAEEVKVPFSYD

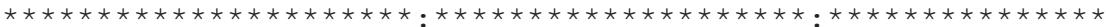

At-ELF 6

Ta-ELF 6

Ta-elf6-1

At-ELF 6

Ta-ELF 6

Ta-elf6-1

At-ELF 6

Ta-ELF 6

Ta-elf6-1

At-ELF 6

Ta-ELF 6

$\mathrm{Ta}-\mathrm{elf} 6-1$

At-ELF 6

Ta-ELF 6

Ta-elf6-1

At-ELF 6

Ta-ELF 6

Ta-elf6-1

At-ELF 6

Ta-ELF 6

Ta-elf6-1

At-ELF 6

Ta-ELF 6

Ta-elf6-1

At-ELF 6

Ta-ELF 6

Ta-elf6-1

At-ELF 6

Ta-ELF 6

Ta-elf6-1

At-ELF 6

Ta-ELF 6

Ta-elf6-1

DVLLESASQEELSLIDLAIEDEEKYEHSVDWTSELGINLRYCVKVRKNSPTKKIQHALSL DILLESASKEELSLIDLA IEDEENNEHGVDWTSKLGINLRYCVKVRKNSPSTKIQHALSL DILLESASKEELSLIDLAIEDEENNEHGVDWTSKLGINLRYCVKVRKNSPSTKIQHALSL

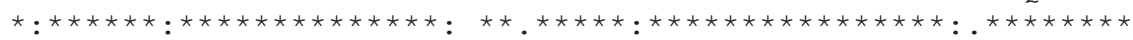

GGLFSDTSQMLDFTT IRWLQRKSRSKAKPSSTSSFTPCEHLEVKADGKLR--DNLDSQTG GGLFSDTNHMLDMST IKWLQRKSRSKAKPSCTSSFTPREHLEVKVDRKLGEKEKVESQAG GGLFSDTNHMLDMST IKWLQRKSRSKAKPSCTSSFTPREHLEVKVDRKLGEKEKVESQAG

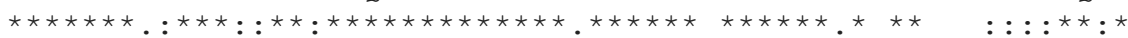

KKEEKIIQYSRKKKLNPKPSAEQVQELATLAKSKDFDKTCKNFSSRSHLDSAIRSEMNSE RKEEKI IQYSRKKKLKPKPSEERSQELTISAKSEDFENTCNTLAKRS HHHGAMHS DMNNE RKEEKI IQYSRKKKLKPKPSEERSQELTISAKSEDFENTCNTLAKRS HHHGAMHS DMNNE

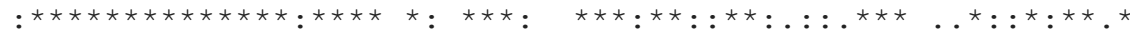

I GDSGRVIGVSFS INPCSSSFTVGHGQEHPEITVKFGSDLDGNVTNS LSMVNGDSADLTL I GDFGR-NGVSFSENHCSSPFTGARGQEHPKII IKFGSALHGNITSSSS LVNGISADLTS IGDFGR-NGVSFSENHCSSPFTGARGQEHPKI I IKFGSALHGNITSSSSLVNG ISADLTS

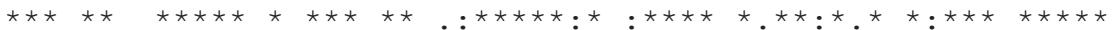

TS ISREQHQGHSMT SNNNGSNSGSHVVASQTILVSTGDNHDGPRKLSGDYVCSDVSVRGI V---TREHQGHSMTSNNNGSNS-------------SNHDGP IKLSGEHV-SDVSVRDV V---TREHQGHSMTSNNNGSNS-------------SNHDGP IKLSGEHV-SDVSVRDV

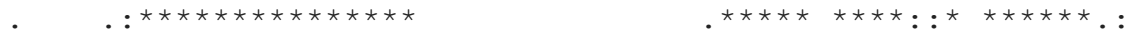

QEAVEMSDQEFGEPRSTVTNIEDEQQSQIVKPTQREAVFGDHEQVEGAEAVSTRENLCSE DEAVEMSDQEFEELRSTVTNIEEEQQSEMVRPTAL--------QVEGEESMCTREILSSE DEAVEMSDQEFEELRSTVTNIEEEQQSEMVRPTAL-------QVEGEESMCTREILSSE

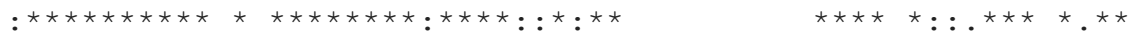

I ILHTEHS--SAHVGME I PDINTASENLVVDMTHDGE PLESS DILSS SNGDEAS SNGLQV DIMHTEQQQEQTQLGLEVPETDIASEN IVVDMI HDDEP LATRDILSSSNGDQASSNGLQA DIMHTEQQQEQTQLGLEVPETDIASEN IVVDMI HDDEPLATRD ILS S SNGDQAS SNGLQA

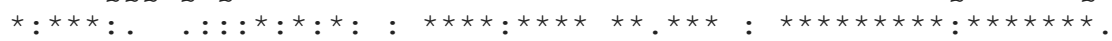

LNDELSMESEVSSSENTEVIEAP--NSMGEAKKKRKIESESETNDNPESS I GFIRSPCEG LDNELSMESEVASSENTEVIEAS PNS IMREANKKRRIESESETNDNP DGS I GF IRSPCEG LDNELSMESEVASSENTEVIEAS PNS IMREANKKRRIESESETNDNPDGS I GF IRSPCEG

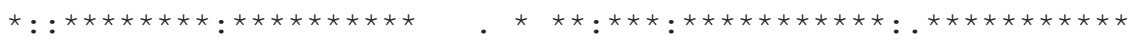

LRSRGKRKATCETSLKHTETSDEEKKP IAKRLKKTPKACSGSRQQEVPTTTHPNRCYLEG LRSRGRRRVTREASVSLTETS DEEKKPAAKREKKTPKTRSGSHHQEDSTTS HHNRCNLEG LRSRGRRRVTREASVSLTETSDEEKKPAAKREKKTPKTRSGSHHQEDSTTSHHNRCNLEG

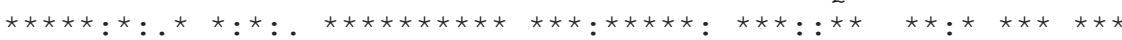

CKMTFESKAKLQTHKRNRCTHEGCGKKFRAHKYLVLHQRVHKDERPFECSWKGCSMTFKW CKMTFKSKAELQAHQRNRCAHEGCGKKFRAHKYLVLHQRVHNDDRP FVCSWKGCSMTEKW CKMTFKSKAELQAHQRNRCAHEGCGKKFRAHKYLVLHQRVHNDDRPFVCSWKGCSMTEKW

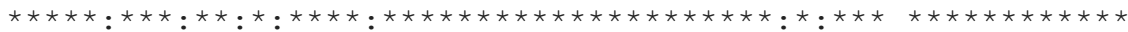

QWARTEHLRLHTGERPY ICKVDGCGLSFRFVSDYSRHRRKTMHYVT PWARTEHLRLHTGERPYKCKVDGCGMSFRFVSDYSRHRRKKGHYVT PWARTEHLRLHTGERPYKCKVDGCGMSFRFVSDYSRHRRKKGHYVT 
bioRxiv preprint doi: https://doi.org/10.1101/609990; this version posted April 16, 2019. The copyright holder for this preprint (which was not certified by peer review) is the author/funder, who has granted bioRxiv a license to display the preprint in perpetuity. It is made available under aCC-BY-NC-ND 4.0 International license.

\begin{tabular}{|c|c|c|}
\hline 294 & \multicolumn{2}{|c|}{ IND - INDEHISCENT (AT4G00120) } \\
\hline & At-IND & MENGMYKKKGVCDSCVSSKSRSNHSPKRSMME \\
\hline & Ta-IND & - - - - - - - - - - - - - - \\
\hline & Ta-ind-1 & $---1--1--1$ \\
\hline & Ta-ind-2 & 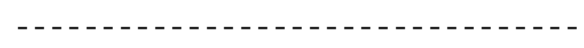 \\
\hline 301 & Ta-ind-3 & - - - - - - - - - - - - - \\
\hline & At-IND & HHLMLDPPPETLIHLDE \\
\hline & Ta-IND & -HLMIDPPPETLSHFQPPPTLFSGHGGEEEEE \\
\hline & Ta-ind-1 & -HLMIDPPPETLSHFQPPPTLFSGHGGEEEEEE \\
\hline & Ta-ind-2 & -HLMIDPPPETLSHFQPPPTLFSGHGGEEEEE \\
\hline & Ta-ind-3 & -HLMIDPPPETLSHFQPPPTLFSGHGGEEEEE \\
\hline 0 & & $* * *: * * * * * * * *::$ \\
\hline & At-IND & ATVPKPNRRNVRISDDPQTVVARRRRERISEK \\
\hline & Ta-IND & ATVPKPNRRNVRVSDDTQTVVARRRREKISEK \\
\hline & Ta-ind-1 & ATVSKPNRRNVRVSDDTQTVVARRRREKISEK \\
\hline & Ta-ind-2 & ATVPKPNKRNVRVSDDTQTVVARRRREKISEK \\
\hline & Ta-ind-3 & $\begin{array}{l}\text { ATVPKPNRRNVRVSDDTQTVVTRRRREKISEK } \\
* * * * * * \cdot * * * * . * * * ; * * * . * * * * * \cdot * * * *\end{array}$ \\
\hline & At-IND & FLKRQVRILQPHSQIGAPMANPSYLCYYHNSQP \\
\hline & Ta-IND & FLKRQVKLLQPHSQLGAPMSDPSCLCYYHNSQT \\
\hline & Ta-ind-1 & FLKRQVKLLQPHSQLGAPMSDPSCLCYYHNSQT \\
\hline & Ta-ind-2 & FLKRQVKLLQPHSQLGAPMSDPSCLCYYHNSQT \\
\hline 132 & Ta-ind-3 & $\begin{array}{l}\text { FLKRQVKLLQPHSQLGAPMSDPSCLCYYHNSQT } \\
* * * * * *:: * * * * * *: * * * *:: * * * * * * * * * *\end{array}$ \\
\hline
\end{tabular}

\title{
AOP2 - alkenyl- and hydroxyalkyl-producing (AT4G03070)
}

\begin{abstract}
At-AOP2
MDSDFVPPSVSFQLPVIDFSDQNLKPGSSKWDEVTADVLKALEDYGCFEASFDKLSVELN Ta-AOP2

Ta-aop2 - - -MGSLSNTPQLPVIYLSDQTLKPGSSKWVEVRSDVRKALEEYGGFEVSYDRVSEELK - - - MGSLSNTPQLPVIYLSDQTLKPGSSKWVEVRSDVRKALEEYGGFEVSYDRVSEELK

$$
\text { : } \quad *: * * * * *: * * * . * * * * * * * * *: * * * * * *: * * * * . * \text { : }^{*}::^{*} * * \text { : }
$$
\end{abstract}

At-AOP2

$\mathrm{Ta}-\mathrm{AOP} 2$

Ta-aop2

At-AOP2

Ta-AOP2

Ta-aop2

At-AOP2

$\mathrm{Ta}-\mathrm{AOP} 2$

Ta-aop2

At-AOP2

Ta-AOP2

Ta-aop 2

At-AOP2

Ta-AOP2

Ta-aop2
RSVFEAMEDLFELPIPTKQRNVSSKPFHGYLCHN-LYESLGINDANVLEKVNDFTQQLWP KSVLQAMEELFALPVEAKQRNVSPKPFSGYSTHNGLSESMGIQDPHVLDKVYEFTQLLRP KSVLQAMEELFALPVEAKQRNVSPKPFSGYSTHNGLSESMRIQDPHVLDKVYEFTQLLRP

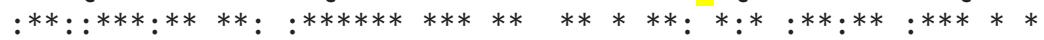

DH - -GNKSISETIHLFSEQLVELDLMVRRMIMESFGIENYIDEHLNSTYY-LTRLMKYTS DHCDGNKSISETIQTFSENADAGVTV--.-- - - -GS - -NADANANANANTSTDAGVGDS DHCDGNKSISETIQTFSENADAGVTV--.-----GS--NADANANANANTSTDAGVGDS ** $* * * * * * * * *: * * *: \quad: \quad * \quad *: *: . \quad * \quad *$ *

PPDDDDDDDEETKLGLRSHTDKNIITILHQYQVDGLEVKTKDDKWIKVKPSQDSVLVMVG VKANGGADDVEKKLGLPSHTDKNLITVLYQYEIEGLEVLTKDDKWIRLKPSHNSFVVMAG VKANGGADDVEKKLGLPSHTDKNLITVLYQYEIEGLEVLTKDDKWIRLKPSHNSFVVMAG $:$. .***.**** ******:**:*:**:: :***********::***::*.:**.*

DSLCALLNGRLHSPYHRVIMTG-KKTRYSTGLFSIPKTGVIIDSPEELVDKEHPRIFKPF DSLYALMNGRLTRPFHRVRVTEKKKTRYSIALFSAPTADYIIDTPKELVDEKHPRIFEPF DSLYALMNGRLTRPFHRVRVTEKKKTRYSIALFSAPTADYIIDTPKELVDEKHPRIFEPF *** **:**** *:*** :* ****** .****.:. ***:*:****::*****:**

EYTDFLHFFQTEAGRIAQSALHAFAAF - - NYNDLMSFYHSEAGRKARSTLDAFCAVSRA NYNDLMSFYHSEAGRKARSTLDAFCAVSRA 
bioRxiv preprint doi: https://doi.org/10.1101/609990; this version posted April 16, 2019. The copyright holder for this preprint (which was not certified by peer review) is the author/funder, who has granted bioRxiv a license to display the preprint in perpetuity. It is made available under aCC-BY-NC-ND 4.0 International license.

\section{FAE1 - FATTY ACID ELONGATION1 (AT4G34520)}

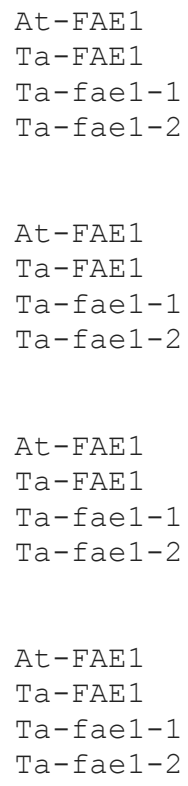

$\begin{array}{ll}1408 & \text { Ta-FAE1 } \\ 1409 & \text { Ta-fae1-1 } \\ 1410 & \text { Ta-fae1-2 }\end{array}$

$\begin{array}{ll}1400 & \text { Ta-FAE1 } \\ 1410 & \text { Ta-fael-1 } \\ 1411 \text { fael-2 }\end{array}$

$\begin{array}{ll}1408 & \text { Ta-FAE1 } \\ 1409 & \text { Ta-fae1-1 } \\ 1410 & \text { Ta-fael-2 }\end{array}$

MTSVNVKLLYRYVLTNFFNLCLFPLTAFLAGKASRLTINDLHNF-LSYLQHNLITVTLLF MTSVNVKLLYHYVITNFFNLCFFPLAA IVAGKASRLTTNDLHHFYYSYLQHNLITISLLF MTSVNVKLLYHYVITNFFNLCFFPLAA IVAGKASRLTTNDLHHFYYSYLQHNLITISLLF MTSVNVKLLYHYVITNFFNLCFFPLAAIVAGKASRLTTNDLHHFYYSYLQHNLITISLLF

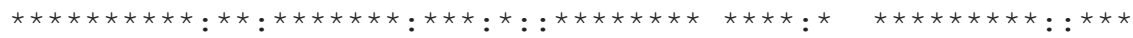

AFTVFGLVLYIVTRPNPVYLVDYSCYLPP PHLKVSVSKVMDIFYQIRKADTSSRNVACDD AFTVFGLALY IVTRPKPVYLVDHSCYLPPSHLRSS ISKVMDI FYQVRLADP-LRNAASDD AFTVFGLALYIVTRPKPVYLVDHSCYLPPSHLRS S ISKVMDI FYQVRLADP-LRNAASDD AFTVFGLALY IVTRPKPVYLVDHSCYLPPSHLRS S ISKVMDI FYQVRLADP-LRNAASDD

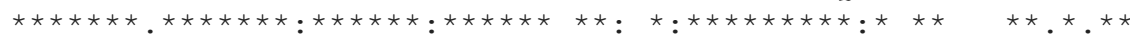

PSSLDFLRKIQERS GLGDETYS PEGL I HVP PRKTFAASREETEKVI I GALENLFENTKVN SSWLDFLRKIQERSGLGDETHGPEGLLQVPPRKTFAAAREETEQVI I GALEKLFENTKVN SSWLDFLRKIQERSGLGDETHGPEGLLQVPPRKTFAAAREETEQVI I GALEKLFENTKVN SSWLDFLRK IQERSGLGDETHGPEGLLQVPPRKTFAAAREETEQVI I GALEKLFENTKVN

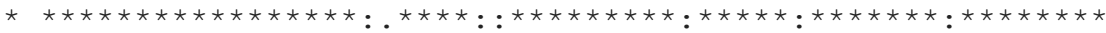

PREIGILVVNSSMFNPTPS LSAMVVNTFKLRSNIKSFNLGGMGCSAGVIAIDLAKDLLHV PKEIGILVVNSSMFNPTPSLSAMVVNTFKLRSNIRSFNLGGMGCSAGVIAIDLAKDLLHV PKEIGILVVNSSMFNPTPSLSAMVVNTFKLRSNIRSFNLGGMGCSAGVIAIDLAKDLLHV PKEIGILVVNSSMENPTPS LSAMVVNTEKLRSNIRS FNLGGMGCSAGVIAIDLAKDLLHV

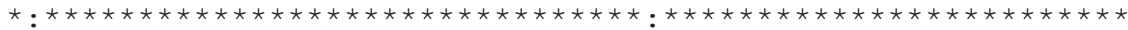

HKNTYALVVSTENITQGIYAGENRSMMVSNCLFRVGGAA ILLSNKS GDRRRSKYKLVHTV HKNTYALVVSTENITYNIYAGDNRSMMVSNCLFRVGGAAILLSNKPRDRRRSKYQLLHTV HKNTYALVVSTENITYNIYAGDNRSMMVSNCLFRVGGAAILLSNKPRDRRRSKYQLLHTV HKNTYALVVSTENITYNIYAGDNRSMMVSNCLERVGGAAILLSNKPRDRRRSKYQLLHTV

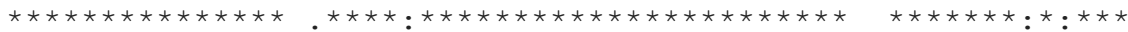

RTHTGADDKSFRCVQQEDDESGKIGVCLSKDITNVAGTTLTKNIATLGPLILPLSEKFLF RTHTGADDKSFRCVQQEDDESGKTGVCLSKDITGVAGRTVQKNITTLGPLVLPFSEKFLF

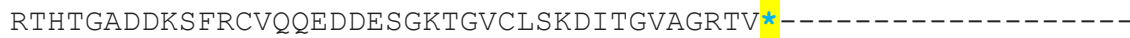
RTHTGADDKSFRCVQQEDDESGKTGVCLSKDITGVAGRTVQKNITTLGPLVLPFSEKFLF

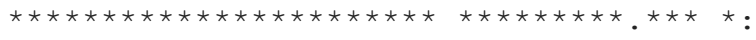

FATFVAKKLLKDKIKHYYVPDFKLAVDHFC I HAGGRAVIDELEKNLGLSP I DVEASRSTL FVTFIAKKLFKDK I KHYYVPDFKLA I DHFC I HAGGRAVI DVLQKNLGLLP I DVEASRSTL

FVTFIAKKLFKDKIKHYYVPDFKLAIDHFC I HAGGRAVI DVLQKNLGLLPIDVEASRSTL

HRFGNTSSSS IWYELAYIEAKGRMKKGNKAWQIALGSGFKCNSAVWVALRNVKASANSPW HRFGNTSSSS IWYELAY IEAKGRMKRGNKVWQIALGSGFKCNSAVWVALRNVKAS TNS PW

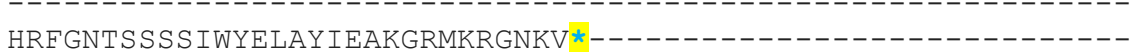

QHCIDRYPVKIDSDLSKSKTHVQNGRSEHCIDRYPDA IDSDSGKSETRVQNGRS *

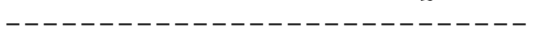

1412 
bioRxiv preprint doi: https://doi.org/10.1101/609990; this version posted April 16, 2019. The copyright holder for this preprint (which was not certified by peer review) is the author/funder, who has granted bioRxiv a license to display the preprint in perpetuity. It is made available under aCC-BY-NC-ND 4.0 International license.

\section{ROD1 - REDUCED OLEATE DESATURATION 1 (AT3G15820) \\ 1414 \\ 1415 At-ROD1 MSAAAAETDVSLRRRSNSLNGNHTNGVAIDGTLDN-NNRRVGDTNTHMDISAKKTDNGYA \\ 1416 Ta-ROD1 ---MSTKTVVPLRRRSKPLNGNHTNGVAIDGSLDDDHNRRIGSVNSQMDNIAKKTDDGYA \\ 1417 Ta-rod1-1 \\ - - -MSTKTVVPLRRRSKPLNGNHTNGVAIDGSLDDDHNRRIGSVNSQMDNIAKKTDDGYA \\ 1418 Ta-rod1-2 \\ - - MSTKTVVPLRRRSKPLNGNHTNGVAIDGSLDDDHNRRIGSVNSQMDNIAKKTDDGYA $::: * * * * * * *: * * * * * * * * * * * * *: * *:: * * *: * . . *:: * * \quad * * * * *: * * *$}

1420

At-ROD1

Ta-ROD1

Ta-rod1-1

Ta-rod1-2

NGVGG-GGWRSKASFTTWTARDIVYVVRYHWIPCMFAAGLLFFMGVEYTLQMIPARSEPF NGGGGGGGGKSKASFMTWTARDVVYVARYHWIPCLFAVGVLFFTGVEYTLQMIPARSEPF NGGGGGGGGKSKASFMTWTARDVVYVARYHWIPCLFAVGVLFFTGVEYTLQMIPARSEPF NGGGGGGGGKSKASFMTWTARDVVYVARYHWIPCLFAVGVLFFTGVEYTLQMIPARSEPF ** ** ** : $* * * * * * * * * * *: * * * . * * * * * * *: * * . *$ : *** $* * * * * * * * * * * * * * * *$

At-ROD1

Ta-ROD1

Ta-rod1-1

DLGFVVTRSLNRVLASSPDLNTVLAALNTVFVGMQTTYIVWTWLVEGRARATIAALFMFT DIGFVATRSLNRVLANSPDLNTVLAALNTVFVGMQTTYIVWTWLMEGRPRATISACFMFT DIGFVATRSLNRVLANSPDLNTVLAALNTVFVGMQTTYIVWTWLMEGRPRATISACFMFT DIGFVATRSLNRVLANSPDLNTVLAALNTVFVGMQTTYIVWTWLMEGRPRATISACFMFT

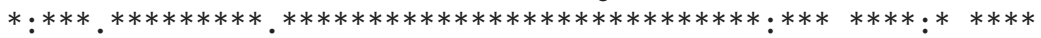

1431

Ta-rod1-2

At-ROD1

Ta-ROD1

Ta-rod $1-1$

CRGILGYSTQLPLPQDFLGSGVDFPVGNVSFFLFFSGHVAGSMIASLDMRRMQRLRLAMV

1433

1434

1435

1436

Ta-rod1-2

CRGILGYSTQLPLPQDFLGSGVDFPVGNVSFFLFYSGHVAGSMIASLDMRRMQRMRLAML CRGILGYSTQLPLPQDFLGSGVDFPVGNVSFFLFYSGHVAGSMIASLDIRRMQRMRLAML CRGILGYSTQLPLPQDFLGSGVDFPVGNVSFFLFYSGHVAGSMIASLDMRRMQRMRLAML

1440

Ta-ROD1

Ta-rod1-1

FDILNVLQSIRLLGTRGHYTIDLAVGVGAGILFDSLAGKYEEMMSKRH-LGTGFSLISKD FDILNVLQSIRLLGTRGHYTIDLAVGVGAGILFDSFAGKYEEMISKRHNLVNGFGLISKD FDILNVLQSIRLLGTRGHYTIDLAVGVGAGILFDSFAGKYEEMISKRHNLVNGFGLISKD

1442 Ta-rod1-2 FDILNVLQSIKLLGTRGHYTIDLAVGVGAGILFDSFAGKYEEMISKRHNLVNGFGLISKD

1443

1444

1445

1446

1447

1448

1449 $* * * * * * * * * *: * * * * * * * * * * * * * * * * * * * * * * * *: * * * * * * *: * * * * * . * * . * * * * *$

At-ROD1 SLVN-

Ta-ROD1 SLVN*

Ta-rod1-1 SLVN*

Ta-rod1-2 SLVN*

1450

1451

1452

1453

1454 